\title{
Hazar Gölü'ndeki (Elazığ/Doğu Türkiye) çökellerin mühendislik özelliklerine ve sualtı kütle hareketlerine genel bir bakış
}

\author{
An overview engineering properties of sediments and submarine mass movements in the \\ Hazar Lake (Elazığ/Eastern Turkey)
}

\author{
Yasemin ASLAN TOPÇUOĞLU ${ }^{1, a}$, Zülfü GÜROCAK ${ }^{* 1, b}$ \\ ${ }^{I}$ Firat Üniversitesi, Mühendislik Fakültesi, Jeoloji Mühendisliği Bölümü, Elazığ/TÜRKIYYE
}

• Geliş tarihi / Received: 12.03.2021 • • Düzeltilerek geliş tarihi / Received in revised form: 29.04.2021 • Kabul tarihi / Accepted: 17.06 .2021

\begin{abstract}
Öz
Bu çalışmanın amacı, Doğu Anadolu Fay Zonu içerisinde yer alan ve Türkiye'nin önemli tektonik göllerinden birisi olan Hazar Gölü yamaçlarındaki çökellerin ve yamaçlarda belirlenen su altı kütle hareketlerinin mühendislik özelliklerinin belirlenmesidir. Bu amaçla, gölde gerçekleştirilmiş olan yüksek çözünürlüklü sığ-sismik veriler kullanılarak belirlenen noktalardan alınan örselenmemiş zemin örneklerinde laboratuvar deneyleri gerçekleştirilmiştir. Deney sonuçlarına göre, akarsuların Hazar Gölü’ne boşaldığı alanlardaki zeminler inorganik iri silt (MLN), gölün orta kesimlerinde ise yüksek plastisiteli silt (MH)'dir. Zeminlerin doygun birim hacim ağırlık değerleri derinlikle artarken, porozite ve boşluk oranı değerleri ise azalmaktadır. MLN sınıfı zeminlerin dayanımı MH sınıfı zeminlere göre oldukça yüksektir. MH sınıfı zeminlerin dayanımı ise yeterince sıkılaşma olmadığından oldukça düşüktür. Hazar Gölü’ne ait sismik profillerde, eğimin dik olduğu yamaçlarda zemin kalınlığı maksimum $3 \mathrm{~m}$ civarında iken, eğimin daha az olduğu yamaçlarda zemin kalınlığı 10 m’ye kadar ulaşabilmektedir. Zemin kalınlığının fazla olduğu yamaçlarda, özellikle zeminin kendi ağırlığı ile gelişmiş su altı kütle hareketleri mevcuttur. Bu kütle hareketleri, plastik deformasyon izlerinin ve dairesel kayma yüzeylerinin açıkça görülebildiği slump tipi kaymalardır. Hazar Gölü yamaçlarındaki zeminlerin oldukça düşük dayanımlı olduğu göz önüne alınırsa, bu kütle hareketlerinin çökellerin kendi ağırlığının etkisiyle kayarak oluştuğunu ve Doğu Anadolu Fay Zonu (DAFZ)'nda meydana gelen depremlerin de bu kütle hareketlerini kolaylaştırdığı söylenebilir.
\end{abstract}

Anahtar kelimeler: Doğu Anadolu fay zonu, Elazığ bölgesi, Hazar gölü, Sualtı kütle hareketi, Zemin

\begin{abstract}
The aim of this study is to determine the engineering properties of the sediments and the submarine mass movements that are formed in the one of the most important tectonic lake of Turkey, Hazar Lake, located in the East Anatolian Fault Zone. For this purpose, laboratory experiments were carried out on undisturbed soil samples taken from the points that were determined by using high-resolution seismic data of the lake. According to the results of the experiments, the soils at the areas where streams discharge into Hazar Lake are Non-Plastic Course Silt (MLN), and around the mid-parts of the lake is High Plastic Silt (MH). Dry unit weight values of soils increase with depth, while porosity and void ratio values decrease. The strength value of MLN is much higher than MH type soils. The strength of MH type soil is quite low since it is not tightened enough. In the seismic profiles of Hazar Lake, the soil thickness is about maximum 3 m on steep slopes, while the soil thickness can reach up to $10 \mathrm{~m}$ on slopes having lower dips. On the slopes where the soil thickness is higher, submarine mass movements developed by the own weight of the soil especially. These types of mass movements are slumptype slides in which traces of plastic deformation and circular failure surfaces are clearly visible. Considering that the soil strength on the slopes of Hazar Lake are very low, it can be said that these mass movements were formed by the weight of the sediments and, the earthquakes that took place in the Eastern Anatolian Fault Zone (DAFZ) also catalyze these mass movements to occur.
\end{abstract}

Keywords: East Anatolian fault zone, Elazlğ region, Hazar lake, Submarine mass movement, Soil

\footnotetext{
${ }^{* b}$ Zülfü GÜROCAK; zgurocak@firat.edu.tr, Tel: (0532) 35536 47, orcid.org/0000-0002-1049-8346

${ }^{\text {a }}$ orcid.org/0000-0002-3135-5926
} 


\section{Giriş}

Torid tektonik birliğinin doğu kesiminde (Ketin, 1966) Doğu Anadolu Fay Zonu (DAFZ) üzerinde yer alan Hazar Gölü (Şekil 1), jeolojik konumu ve oluşum şekli bakımından günümüze değin birçok araştırmacının dikkatini çekmiş ve bölgede farklı jeolojik amaçlara yönelik olarak birçok çalışma (Huntington, 1902; Arpat ve Şaroğlu, 1972; Perinçek, 1979a, 1979b; Hempton vd., 1983; Dunne ve Hempton, 1984; Hempton, 1984, 1985; Jackson ve McKenzie, 1984; Yazgan, 1984; Sungurlu vd., 1985; Şengör vd., 1985; Herece ve Akay, 1992; Lyberis vd., 1992; Şaroğlu vd., 1992; Gürocak, 1993; Kaya, 1993, 2004; Nalbant vd., 2002; Çetin vd., 2003; Westaway, 2003; Kaymakc1 vd., 2006; Yılmaz vd., 2006; Aksoy vd., 2007; Duman ve Emre, 2013; Kaymakc1 vd., 2010; Köküm ve İnceöz, 2018) gerçekleştirilmiştir. Jeolojik olarak ilgi çeken ve çok fazla araştırmanın yapıldığı Hazar Gölü ve çevresinde yapılan bu çalışmalar incelendiğinde, bu çalışmaların genel olarak Hazar Gölü'nün oluşumu, DAFZ'nin yapısal özellikleri, bölgenin jeolojisi ve jeodinamiği ile ilgili olduğu görülmektedir. Doğrudan Hazar Gölü ile ilgili çalışmalar (Moreno vd., 2011; Aslan, 2013; Eriş, 2013; Eriş vd., 2018a, 2018b; Bal Akkoca vd., 2019; Canpolat vd., 2020) ise 2010 yılından itibaren hız kazanmıştır. Bu çalışmalar, genel olarak Paleo-iklim, sedimantoloji ve jeokimya konularındadır. Hazar Gölü'nün oluşumundan günümüze değin gölün yamaç ve tabanında çökelen ve hala çökelmeye devam eden çökellerin mühendislik özellikleri ve Hazar Gölü yamaçlarında varlığı sismik verilerle ortaya konan sualtı kütle hareketleri konusunda ise günümüze değin yapılan herhangi bir çalışma bulunmamaktadır.

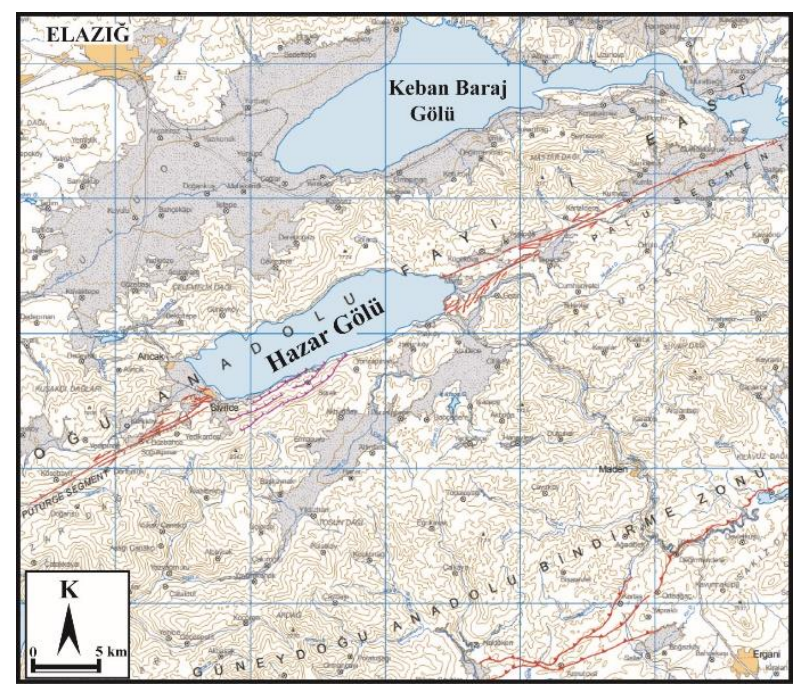

Şekil 1. Hazar Gölü’nün yer belirleme haritas1 (MTA, 2012)
Dünya'da özellikle 1980'lerden sonra denizaltı sedimentleri ve kütle hareketleri konusunda yapılan çalışmaların (Auffret vd., 1982; Cochonat vd., 1993; Lee vd., 1993; Mulder vd., 1994; Elverhøi vd., 1997; Imran vd., 2001a, 2001b; Kim ve Kim, 2001; Hühnerbach ve Masson, 2004; Rajasekaran, 2006; Stegmann vd., 2006; Yun vd., 2006; Förster vd., 2007; Stegmann, 2007; Förster vd., 2008; Winters vd., 2008; Lee, 2009; Ioualalen vd., 2010; Förster vd., 2010a, 2010b; Förster, 2011; Strozky vd., 2010; Lee vd., 2011; Ai vd., 2014; Kopf vd., 2016; Stegmann ve Kopf, 2017) artarak günümüze değin devam ettiği görülmektedir. Araştırmacılar bu çalışmalarda, genellikle sualtı kütle hareketleri ve oluşum mekanizlamaları ile denizaltı çökellerinin mühendislik özellikleri konusunda araştırma yapmışlardır. Türkiye'de ise bu konudaki çalışmaların 1999 Marmara Depremi'nden sonraki yıllarda başladığını ve özellikle Kuzey Anadolu Fay Zonu (KAFZ)'nun içerisinden geçtiği Marmara Denizi'nde yoğunlaştığını görmek mümkündür. $\mathrm{Bu}$ çalışmalarda (Alpar, 1999; Çağatay vd., 1999; Sarı ve Çağatay, 2001, 2006; Başaran, 2002; Tolun vd., 2002; Gazioğlu vd., 2005; Eriş vd., 2007; Görür vd., 2008; Gökçeoğlu vd., 2009; Kuşçu vd., 2009) Marmara Denizi havzasının kuzey yamaçlarındaki denizaltı sedimentlerinin özellikleri, bölgenin depremselliği ve yine aynı yamaçta gelişmiş olan sualtı kütle hareketlerinin oluşum mekanizması ile bu hereketlere bağlı olarak gelişebilecek tsunamilerin olası etkileri araştırılmıştır. Görüldüğü gibi Türkiye'de bu konuda yapılan çalışmalar daha çok Marmara Denizi ile sınırlı kalmıştır. Hazar Gölü ile ilgili en kapsamlı çalışma 2011-2014 yılları arasında gerçekleştirilmiştir. $\mathrm{Bu}$ çalışma (TÜBİTAK, 2014) kapsamında Hazar Gölü’nde sismik çalışmalar gerçekleştirilmiş, sualtından zemin örnekleri alınmış, bu örneklerin sedimantolojik ve jeokimyasal özellikleri incelenmiştir. Ayrıca, Aslan (2013) tarafindan gerçekleştirilen çalışmada Hazar Gölü'ne ait sedimanların jeoteknik özellikleri incelenmiştir.

Bu çalışmada, Türkiye'nin en önemli tektonik göllerinden birisi olan Hazar Gölü yamaçlarında birikmiş olan çökellerin mühendislik özellikleri ile daha önce yapılan sismik çalışmalarda belirlenmiş olan sualtı kütle hareketlerinin genel özellikleri irdelenmiştir. $\mathrm{Bu}$ amaçla, göl yamaçlarından alınan örselenmemiş zemin örneklerinde laboratuvar deneyleri gerçekleştirilmiş, ayrıca sismik veriler kullanılarak gölün yamaçlarındaki kütle hareketlerinin genel özellikleri açılanmaya çalışılmıştır. 


\section{Bölgenin genel jeolojik özellikleri}

Hazar Gölü, Türkiye'nin en önemli ikinci yapısal unsuru olan, sol yanal atımlı DAFZ üzerinde yer alır (Şekil 1) ve Orta Miyosen'den günümüze aktivitesini sürdüren Türkiye neotektoniğinin ana elemanlarından bir olma özelliğindedir. Bölgede, Orta Miyosen'den (Serravaliyen) itibaren Arabistan ve Avrasya levhalarının çarpışması sonucu Tetis Okyanusu'nun kapanmasi ile neotektonik dönem başlamış (Şengör vd., 1985) ve Doğu Anadolu Bölgesi, kıta içi sıkışma rejimi neticesinde meydana gelen deformasyon sonucu yükselmiştir. Böylece, sıkışmanın etkisiyle Anadolu levhacığı iki yanal atımlı fay boyunca batıya doğru kaçmaya başlamış ve KAFZ ile DAFZ oluşmuştur.

Karlıova üçlü eklem noktasından başlayan DAFZ, Bingöl, Palu, Hazar Gölü, Pötürge, Sincik, Narlı, Türkoğlu yörelerinden geçerek İskenderun körfezine kadar uzanmaktadır. KuzeydoğuGüneybatı doğrultusunda uzanan bu zon yaklaşık $700 \mathrm{~km}$ uzunluğunda ve $30 \mathrm{~km}$ genişliktedir (Arpat ve Şaroğlu, 1972; Koçyiğit vd., 2003; Aksoy vd., 2007). Bu zon içerisinde çok sayıda ana kırıklara paralel veya yarı paralel sıçrama (step over), ayrılma, bükülme (bending) ve yön değiştirmeler gösteren sol yanal atımlı faylar da bulunmaktadır. Ayrıca bu yapılar arasında dere ötelenmelerini, fay yamaçlarını, dönmüş (rotated) fay vadi ve sırtlarını, as1l vadileri (hanging valleys), heyelanları, su kaynaklarını ve yanal atımlı havzaları (strike-slip basins) görmek mümkündür (Çetin vd., 2003). Bunlardan en önemlisi de Hazar Gölü (çek-ayır) havzasıdır. Hazar Gölü ve çevresinde yaşı Paleozoik'den Güncel'e kadar değişen formasyonlar yüzeylemekte ve Paleozoik-Eosen yaşlı kayaçlar Hazar Gölü havzasının temelini oluşturmaktadır (Şekil 2).

Bölgede en yaşlı birimi Paleozoik-Mesozoik yaşlı Pötürge Metamorfitleri oluşturuken, bu metamorfitler üzerinde allokton konumda JuraErken Kretase yaşlı Guleman ofiyolitleri ve Senoniyen yaşlı Elazı̆ Magmatitleri yer almaktadır. Bu formasyonlar üzerinde ise uyumsuz olarak Maestrihtiyen-Geç Paleosen yaşlı Hazar grubuna ait flișler ile Orta Eosen yaşlı Maden Karmaşığı'na ait volkano-sedimentler yüzeylemektedir. Bölgedeki en genç birimler ise Pliyo-Kuvaterner yaşlı ve güncel alüvyonlardır.

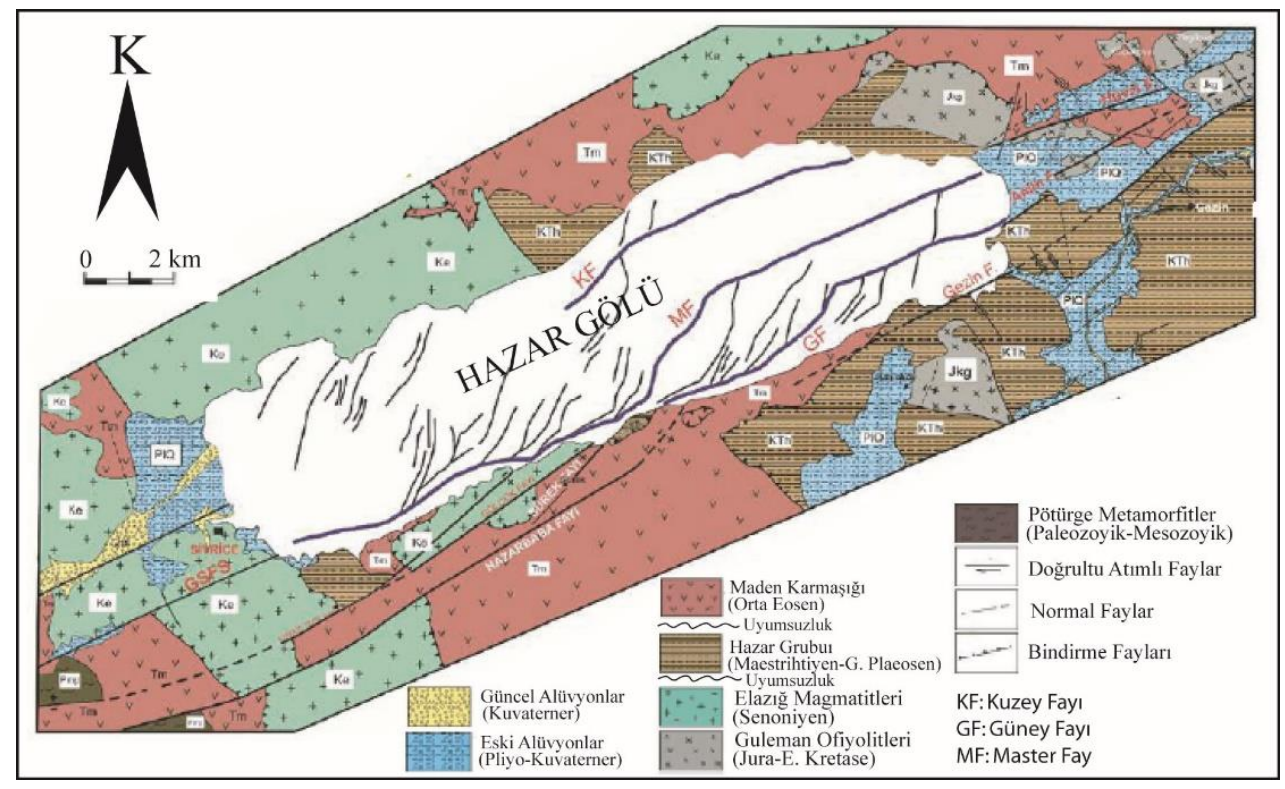

Şekil 2. Hazar Gölü ve yakın çevresinin jeoloji haritası (Gürocak, 1993; Kaya, 1993; Aksoy vd., 2007 ve MTA, 2008'den yararlanılarak hazırlanmıştır).

\section{Hazar Gölü'nün batimetrik ve morfo- tektonik özellikleri}

Hazar Gölü'nün morfolojik ve yapısal özelliklerini belirlemek amacıyla yapılan en önemli çalışma Moreno vd., (2011) tarafından gerçekleştirilmiştir. Hazar Gölü'nde yapılan en detaylı batimetri çalışmaları ise TÜBİTAK (2014) projesi kapsamında yapılmıştır. $\mathrm{Bu}$ çalışmalarda elde edilen sı̆̆g-sismik görüntü verilerinden göl tabanının morfolojisi, sualtı kütle hareketleri, basınç sırtları, horst-graben yapıları, eski vadi tabanları, faylanmalar, kıvrımlı yapılar ve eski gölsel taraçalar gibi morfolojik yapılar belirlenmiştir (Şekil 3). Bu verilere göre Hazar Gölü doğu ve batı olmak üzere iki farklı çökelme havzasına sahiptir. Gölün Batı Havzası'nın en derin kesimi -70 m'lerdedir ve doğuya doğru 
derinleşerek -232 m derinliğe ulaşan Doğu Havzası'na geçilmektedir. Gölün güney ve doğu yamaçları, kuzey ve batı yamaçlarına göre daha diktir. Ayrıca, DAFZ'nin bu bölgedeki aktif kolları Hazar-Sincik ve Palu-Hazar segmentlerinin gölün içerisindeki güzergâhları da yapılan çalışmalarla ortaya çıkarılmıştır. Hazar Gölü'nün güney yamacına yakın bir güzergâh izleyen bu segmentler nedeniyle gölün güney yamaçları oldukça diktir. Elde edilen verilere göre DAFZ'ye ait GezinSivrice Fay Sistemi gölün batısından göle girerek yaklaşık $4.5 \mathrm{~km}$ gölün güney kıyısına paralel olarak devam ettikten sonra orta kesiminde iki ana kola ayrilmaktadır (Aksoy vd., 2007). Bu iki kolun en güneydeki Güney Fay ve kuzeydeki diğer kol ise Master Fay olarak isimlendirilmiştir. Master Fayı gölün ortasında büklüm yaparak doğuya doğru devam etmekte ve gölün doğusunda karaya çıkmaktadır. Bu fay yapılan çalışmalarda (Çetin vd., 2003; Aksoy vd., 2007) Havri Fayı olarak adlandırılmıştır. Gölün doğusundan karaya çıkan Güney Fay (GF) ise Aidin Fayı olarak adlandırılmıştır. Hazar Gölü'nün kuzey kesiminde ise normal fay karakterindeki Kuzey Fayı (KF) yer almaktadır. Göl içersindeki ana fayın 15 m'ye ulaşan düşey bileşene sahip olduğu ve bu ana fayın kuzeyinde ve güneyinde gelişen normal faylarda ise 70 m'ye ulaşan düşey atımlar görülmektedir. Hazar Gölü'nün GD'sunda göl çökellerinde gelişen basınç sırtları da yer almaktadır. Gölün Doğu Havzası'nda ana fayın kuzey ve güneyindeki normal faylar, bölgenin gerilmeli bir tektonik rejimde derinleștiğini göstermesi açısından önemlidir. Yapılan çalışmalarda oluşturulan sismik kesitlerde bu bölgenin aktif bir tektonizma etkisinde olduğunu gösteren ve gölün özellikle güney yamaçlarında gelişmiş çok sayıda su altı kütle hareketleri bulunmaktadır.

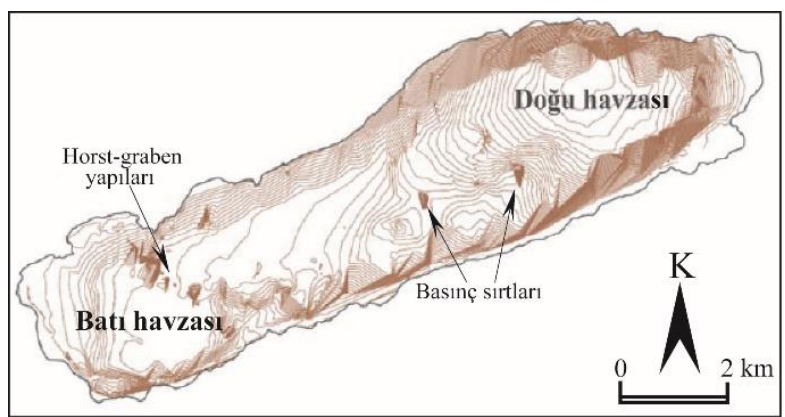

Şekil 3. Hazar Gölü'ne ait batimetri haritası (TÜBİTAK, 2014)

\section{Zemin örneklerinin derlenmesi ve laboratuvar deneyleri}

Herhangi bir deniz veya gölden zemin örneklemesinin yapılabilmesi için öncelikle örnekleme noktalarının belirlenmesi gereklidir. $\mathrm{Su}$ altındaki bu noktaların belirlenmesi ise yapılacak olan sismik çalışmalar ile mümkündür. Hazar Gölü tabanı ve yamaçlarındaki temel kaya ve çökeller hakkında bilgi elde etmek ve böylece örnekleme noktalarını belirlemek amacıyla gerçekleştirilen proje (TÜBITAK, 2014) kapsamında yüksek çözünürlüklü sı ğ-sismik çalışmalar yapılmıştır. Bu çalışmalar ile toplam $65 \mathrm{~km}$ uzunluğunda 23 adet sı̆̆-sismik profil alınmıştır (Şekil 4).

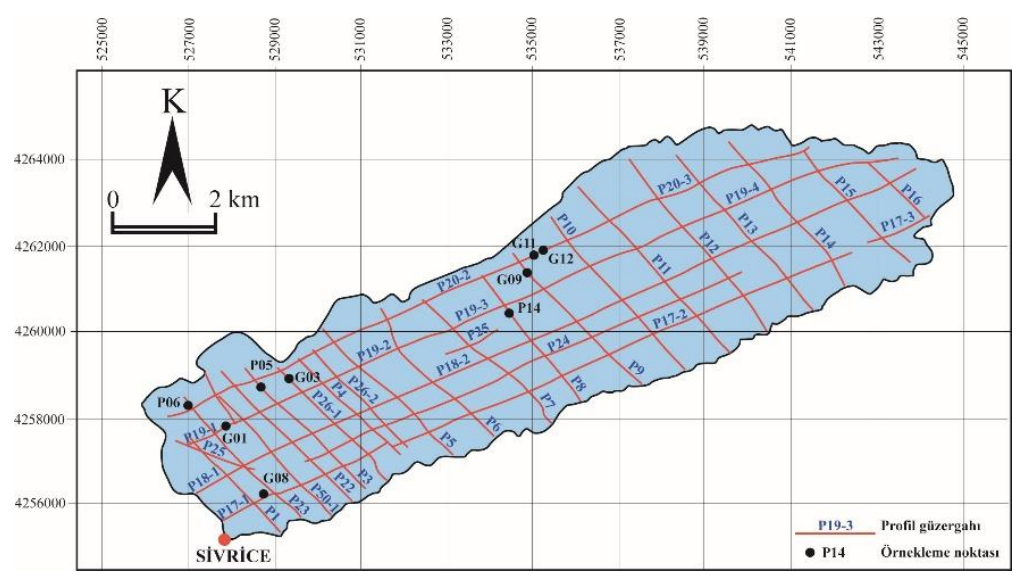

Şekil 4. Sı ̆̆-sismik kesit güzergâhları ve örnekleme noktaları (TÜBİTAK, 2014)

Yapılan sı̆̆-sismik çalışmalara ait görüntülerin değerlendirilmesi sonucunda belirlenen noktalardan çakmalı piston ve gravite yöntemleriyle alınan örselenmemiş zemin örneklerinden seçilen 9 örnekte laboratuvar deneyleri gerçekleştirilmiştir. Seçilen bu örneklere ait bilgiler Tablo 1'de verilmiştir. 
Tablo 1. Hazar Gölü’nden alınan örneklere ait bilgiler (TÜBİTAK, 2014)

\begin{tabular}{cccccc}
\hline $\begin{array}{c}\text { Örnek } \\
\text { No }\end{array}$ & Örnekleme Ad1 & Lokasyon & $\begin{array}{c}\text { Örnek } \\
\text { Uzunluğu } \\
(\mathrm{m})\end{array}$ & $\begin{array}{c}\text { Derinlik } \\
(-\mathrm{m})\end{array}$ & Örnek Alma Yöntemi \\
\hline 1 & HZ11-G01 & & 0.67 & $48.00-48.67$ & Gravite \\
2 & HZ11-G03 & Gölün Bat1 & 0.98 & $56.31-57.29$ & Gravite \\
3 & HZ11-G08 & Kesimi & 0.60 & $19.98-20.58$ & Gravite \\
4 & HZ11-P05 & & 2.25 & $37.50-39.75$ & Piston Çakmal1 \\
5 & HZ11-P06 & & 2.57 & $11.50-14.07$ & Piston Çakmal1 \\
\hline 6 & HZ11-G09 & & 1.08 & $64.00-65.08$ & Gravite \\
7 & HZ11-G11 & Gölün Orta & 1.08 & $65.00-66.08$ & Gravite \\
8 & HZ11-G12 & Kesimi & 0.79 & $71.50-72.29$ & Gravite \\
9 & HZ11-P14 & & 2.07 & $77.00-79.07$ & Piston Çakmal \\
\hline
\end{tabular}

Hazar Gölü’nde yapılmış olan çalışmalarda (Eriş, 2013; Eriş vd., 2018a) Holosen yaşlı olduğu belirlenen bu zemin örneklerinde birim hacim ağılık, su içeriği, özgül ağılık, likit limit, plastik limit ve doğrudan kesme deneyleri gerçekleştirilmiştir.

Bilindiği gibi, dane boyu dağılımı analizlerinde, dane çapının 0.075 mm'den büyük olduğu zeminlerin (kum ve çakı1) dane boyu dağılımı elek analizi yöntemi ile belirlenirken, $0.075 \mathrm{~mm}$ 'den küçük danelere sahip olan zeminlerinde ise Stokes yasasına dayanan çökeltme (hidrometre) yöntemi kullanılmaktadır. Ancak, bu yöntemin uzun zaman alması (en az 2 gün) ve Stokes yasasının bazı kabullerinden dolayı sonuçlarının bir miktar hatalı olması gibi dezavantajları bulunmaktadır (Zhang ve Tumay, 1995; Bardet, 1997; Vitton ve Sadler, 1997; Lu vd., 2000; Wen vd., 2002). Bu nedenlerden dolayı, son yıllarda klasik yöntemlere alternatif yeni yöntemler geliştirilmiştir. $\mathrm{Bu}$ yöntemlerden bazıları, elektrodirenç dane sayımı (Coulter Counter), fotometrik teknikler (Hydrophotometer), $\mathrm{X}$-1şınları azalımı (Sedigraph) ve lazer kırınım (Microtrac, Malvern Master Sizer 3000, Coulter LS) yöntemleridir (Beuselinck vd., 1998). En çok kullanılan yöntem ise lazer kırınım yöntemidir (Wen vd., 2002) ve günümüzde aşındırma, seramik, çimento, kum, kil, gıda, ilaç sanayi, kozmetik vb. gibi birçok mühendislik ve endüstri alanında kullanılmaktadır (Ma vd., 2000). $10 \mathrm{~nm}-3.5 \mathrm{~mm}$ aralığındaki danelerin ölçülebildiği lazer kırınım yöntemi klasik yöntemlere kıyasla daha kısa sürede gerçekleştirilebilmekte ve daha sağlıklı sonuçlar vermektedir. Bu çalışmada zeminlerin dane boyu dağılımını belirleyebilmek için Malvern Mastersizer 3000 lazer kırınım cihazı kullanılmıştır. $\mathrm{Bu}$ yöntemde, öncelikle parçacık boyu analizi yapılacak malzemenin refraktif indeks (kırılma indisi) değeri ve absorbans Malvern'e ait "refractive index guide" kitapçığından belirlenmekte ve örneğe sıvı ünitede bakılacak ise, eneme dispersiyonu hazırlanmaktadır. Örneğin çözelti içerisinde asılı halde kalması için beherdeki örnek spatula ile karıştırarak, surfaktant vb kimyasallar eklenir. Homojen hale getirilen örnekten spatulanın ucuyla yeteri kadar alınarak aletin haznesine boşaltılır. Ultrasonik enerji ve mekanik karıştırıcının etkisiyle zemin topaklarının ayrışması için yaklaşık 4-5 dakika beklendikten sonra, bilgisayar yazılımından uygun komut kullanılarak analiz gerçekleştirilir ve sonuçların çıktısı alınır.

Tablo 2. Zemin örneklerine ait dane boyu dağılımı analiz sonuçları

\begin{tabular}{|c|c|c|c|c|c|c|}
\hline \multicolumn{2}{|c|}{$\begin{array}{l}\text { Örnek } \\
\text { No }\end{array}$} & $\begin{array}{c}\text { Örnekleme } \\
\text { Adı }\end{array}$ & $\begin{array}{l}\text { Kil } \\
(\%)\end{array}$ & $\begin{array}{l}\text { Silt } \\
(\%)\end{array}$ & $\begin{array}{c}\text { Kum } \\
(\%)\end{array}$ & $\begin{array}{c}\text { Çakıl } \\
(\%)\end{array}$ \\
\hline \multicolumn{2}{|c|}{1} & HZ11-G01 & 10 & 85 & 5 & - \\
\hline \multicolumn{2}{|l|}{2} & HZ11-G03 & 10 & 83 & 7 & - \\
\hline \multicolumn{2}{|l|}{3} & HZ11-G08 & 13 & 87 & - & - \\
\hline \multirow{3}{*}{4} & (a) & & 3 & 79 & 18 & - \\
\hline & (b) & HZ11-P05 & 2 & 68 & 30 & - \\
\hline & (c) & & - & 65 & 35 & - \\
\hline \multirow{4}{*}{5} & (a) & \multirow{4}{*}{ HZ11-P06 } & 3 & 82 & 15 & - \\
\hline & (b) & & 3 & 77 & 20 & - \\
\hline & (c) & & 3 & 77 & 20 & - \\
\hline & (d) & & 9 & 51 & 38 & 2 \\
\hline \multirow{3}{*}{6} & (a) & \multirow{3}{*}{ HZ11-G09 } & 18 & 82 & - & - \\
\hline & (b) & & 8 & 84 & 8 & - \\
\hline & (c) & & 10 & 80 & 10 & - \\
\hline \multirow{3}{*}{7} & (a) & \multirow{3}{*}{ HZ11-G11 } & 10 & 85 & 5 & - \\
\hline & (b) & & 7 & 81 & 12 & - \\
\hline & (c) & & 4 & 81 & 15 & - \\
\hline \multirow{2}{*}{8} & (a) & \multirow{2}{*}{ HZ11-G12 } & 10 & 85 & 5 & - \\
\hline & (b) & & 13 & 69 & 18 & - \\
\hline \multirow{4}{*}{9} & (a) & \multirow{4}{*}{ HZ11-P14 } & 10 & 70 & 20 & - \\
\hline & (b) & & 10 & 80 & 10 & - \\
\hline & (c) & & 5 & 75 & 20 & - \\
\hline & (d) & & 10 & 78 & 12 & - \\
\hline
\end{tabular}

Örneklerin dane boyu dağ 1 lım analizlerinde, 3.5 $\mathrm{mm}$ den daha büyük daneler içerdiği için 6 nolu örnekte ASTM D 422-63 (2007) standardına göre yapılan elek analizi yöntemi ve lazer kırınım yöntemi birlikte kullanılmıştır. Diğer örneklerde ise sadece lazer kırınım yöntemi kullanılmıştır. 
Analizler sonucunda elde edilen dane çapı dağılım yüzdeleri Tablo 2'de verilmiştir. Analiz sonuçlarına göre, tüm zemin örnekleri büyük oranda siltten oluşmaktadır. 1, 2 ve 3 nolu örneklerde kum yok denecek kadar az iken, 4 ve 5 nolu örneklerde ise kum oranı kilden daha fazladır. 6, 7, 8 ve 9 nolu örneklerde ise kil ve kum oranı hemen hemen aynidir.

Zemin örneklerinin likit limit (LL) ve plastik limitleri (PL) ASTM D4318 (2017) standardına göre yapılan deneyler ile belirlenmiş ve zemin örnekleri ASTM 2487 (2017) tarafindan önerilen Birleştirilmiş Zemin Sınıflama Sistemi (USCS)'ne göre sınıflandırılmıştır (Tablo 3). Yapılan sinıflamaya göre 1, 2, 3, 6, 7 ve 8 nolu örneklerin sınıfı yüksek plastisiteli silt $(\mathrm{MH})$ olarak belirlenmiştir. Ancak, 4 ve 5 nolu örnekler ile 9 nolu örneğin orta seviyesinden alınan örneklerin LL ve PL değerleri belirlenememiştir. $\mathrm{Bu}$ nedenle, örnekler USCS'ye göre sinıflandırılamamış ve bu örneklerin sinıflandırılmasinda Prakash ve Sridharan (2012) tarafindan plastik olmayan (Nonplastik) zeminler için önerilen sınıflama sistemi kullanılmıştır. Bu sınıflama sistemi ile hem nonplastik ince dane içeren iri daneli zeminler hem de non-plastik ince daneli zeminler sinıflandırılabilmektedir. 4 ve 5 ile 9 nolu örneğin orta seviyesinden alınan örnekler için yapılan siniflama sonucunda örneklerin zemin sinifi inorganik iri silt (MLN) olarak belirlenmiştir.

Örnekleme noktaları ile zemin sınıfı arasındaki ilişki incelendiğinde (Şekil 4), zemin sınıfi ile örnekleme noktaları arasında bir ilişkini olduğunu görmek mümkündür. Nitekim Hazar Gölü'nün batısında göle giren ve malzeme taşıyan Kürk Çayı'nın göle giriş yaptığ 1 alandan alınan örneklerde kum ve silt oranının artması nedeniyle zemin sınıfı MLN'dir. 9 nolu örnek hariç diğer örnekleme noktaları gölün orta kesimlerinde ve kıyıdan uzaktadır. Akarsularla göle taşınan iri malzeme bu alanlara ulaşamadan çökeldiği için bu örnekleme noktalarından alınan örneklerin zemin sınıfi MH'tır. 9 nolu örneğin alındığı örnekleme noktası (Şekil 4) kıyıdan uzak olmasına karşın, bu örneğin orta seviyelerinde kum ve silt oranının yüksek olması nedeniyle zemin non-plastik özelliktedir. Bu durum, geçmiște göle aşırı malzeme girişi olduğunu ve böylece iri danelerin gölün orta kısımlarına kadar yayıldığını göstermesi açısından önemlidir.

Tablo 3. Zemin örneklerinin kıvam limitleri ve sınıflandırılması

\begin{tabular}{|c|c|c|c|c|c|c|}
\hline \multicolumn{2}{|c|}{$\begin{array}{c}\text { Örnek } \\
\text { No }\end{array}$} & $\begin{array}{c}\text { Örnekleme } \\
\text { Adı }\end{array}$ & LL $(\%)$ & PL (\%) & PI (\%) & $\begin{array}{c}\text { Zemin } \\
\text { Sinıfi }\end{array}$ \\
\hline 1 & & HZ11-G01 & 58.00 & 33.34 & 24.66 & $\mathrm{MH}$ \\
\hline 2 & & HZ11-G03 & 64.80 & 34.46 & 30.34 & MH \\
\hline 3 & & HZ11-G08 & 50.60 & 31.38 & 19.22 & $\mathrm{MH}$ \\
\hline 4 & $\begin{array}{l}\text { (a) } \\
\text { (b) } \\
\text { (c) }\end{array}$ & HZ11-P05 & & Yapılamadi & & MLN \\
\hline 5 & $\begin{array}{l}\text { (a) } \\
\text { (b) } \\
\text { (c) } \\
\text { (d) }\end{array}$ & HZ11-P06 & & Yapılamadi & & MLN \\
\hline 6 & $\begin{array}{l}\text { (a) } \\
\text { (b) } \\
\text { (c) }\end{array}$ & HZ11-G09 & $\begin{array}{l}68.20 \\
75.80 \\
77.80 \\
\end{array}$ & $\begin{array}{l}38.72 \\
41.31 \\
40.91 \\
\end{array}$ & $\begin{array}{l}29.48 \\
34.49 \\
36.89 \\
\end{array}$ & MH \\
\hline 7 & $\begin{array}{l}\text { (a) } \\
\text { (b) } \\
\text { (c) }\end{array}$ & HZ11-G11 & $\begin{array}{l}58.40 \\
82.00 \\
92.60 \\
\end{array}$ & $\begin{array}{l}37.49 \\
43.23 \\
56.72 \\
\end{array}$ & $\begin{array}{l}20.91 \\
38.77 \\
35.88 \\
\end{array}$ & MH \\
\hline 8 & $\begin{array}{l}\text { (a) } \\
\text { (b) }\end{array}$ & HZ11-G12 & $\begin{array}{l}71.30 \\
70.00 \\
\end{array}$ & $\begin{array}{l}43.39 \\
39.58 \\
\end{array}$ & $\begin{array}{l}21.91 \\
30.42 \\
\end{array}$ & MH \\
\hline 9 & $\begin{array}{l}\text { (a) } \\
\text { (b) } \\
\text { (c) } \\
\text { (d) }\end{array}$ & HZ11-P14 & 78.00 & $\begin{array}{c}45.64 \\
\text { Yap1lamad1 } \\
66.52 \\
\end{array}$ & 32.36 & $\begin{array}{c}\text { MH } \\
\text { MLN } \\
\text { MH }\end{array}$ \\
\hline
\end{tabular}

Zemin örneklerinin doygun birim hacim ağırlığ $1\left(\gamma_{d}\right)$ ASTM D4531-86 (2010), doğal su içeriği (w) ASTM D2216 (2019), özgül ağırlığı (Gs) ise ASTM D854-02 (2014) standartlarına göre yapılan deneyler ile belirlenmiştir. Ayrıca, zeminin kohezyon (c) ve içsel sürtünme açılarını ( $\phi)$ belirlemek amaciyla ASTM D3080/D3080M
(2011) standardına göre drenajsız doğrudan kesme deneyleri gerçekleştirilmiştir. Deneylere ait sonuçlar Tablo 4 ve 5'de verilmiştir.

MH sınıfi zeminlerin doygun birim hacim ağrilığ $12.65-15.79 \mathrm{kN} / \mathrm{m}^{3}$, su içeriği \% 62.70-170.24, boşluk oranı $\% 173.89-425.53$, porozitesi \% 63.29- 
80.95, özgül ağırlığ1 ise 2.23-2.70 arasında değişmektedir. Zemin örnekleri oldukça düşük kohezyon ve içsel sürtünme açısına sahiptir. Kohezyon değeri en fazla $25.50 \mathrm{kPa}$ iken, $\phi$ değerleri $0^{\circ}-11^{\circ}$ arasında değişmektedir.

MLN sınıfindaki zeminin doygun birim hacim ağırlığı 12.45-18.73 kN/m³ , su içeriği \% 27.71-
141.38, boşluk oranı \% 81.85-349.15, porozitesi \% 45.01-77.73 ve özgül ağırlığı ise 2.36-2.78 değerleri arasındadır. Zemin örnekleri MH sınıfı zemine göre daha düşük $\mathrm{c}$, daha yüksek $\phi$ değerlerine sahiptir. Maksimum c değeri $15.69 \mathrm{kPa}$ iken, maksimum $\phi$ değeri ise $35^{\circ}$ olarak belirlenmiştir.

Tablo 4. MH sınıfindaki zeminlere ait laboratuvar sonuçları ve istatistiksel değerlendirme

\begin{tabular}{|c|c|c|c|c|c|c|c|c|c|}
\hline Örnek No & $\begin{array}{c}\text { Örneklem } \\
\text { Adı }\end{array}$ & & $\begin{array}{c}\gamma_{d} \\
\left(k N / m^{3}\right)\end{array}$ & $\begin{array}{l}\mathrm{w} \\
(\%)\end{array}$ & $\begin{array}{c}\mathrm{e} \\
(\%)\end{array}$ & $\begin{array}{c}\mathbf{n} \\
(\%)\end{array}$ & Gs & $\begin{array}{c}\phi \\
\left({ }^{0}\right)\end{array}$ & $\begin{array}{c}\mathbf{c} \\
(\mathbf{k P a})\end{array}$ \\
\hline 1 & HZ11-G01 & & 15.20 & 87.30 & 215.50 & 68.24 & 2.61 & 11.00 & 3.92 \\
\hline 2 & HZ11-G03 & & 15.50 & 82.12 & 191.91 & 65.67 & 2.53 & 0.00 & 25.50 \\
\hline 3 & HZ11-G08 & & 15.79 & 62.70 & 173.89 & 63.29 & 2.70 & 4.00 & 3.43 \\
\hline \multirow{3}{*}{6} & \multirow{3}{*}{ HZ11-G09 } & (a) & 13.14 & 170.24 & 425.53 & 80.95 & 2.59 & 1.00 & 1.77 \\
\hline & & (b) & 13.44 & 156.37 & 397.09 & 79.57 & 2.64 & 1.00 & 1.86 \\
\hline & & (c) & 13.53 & 154.97 & 383.68 & 78.96 & 2.60 & 8.00 & 1.96 \\
\hline \multirow{3}{*}{7} & \multirow{3}{*}{ HZ11-G11 } & (a) & 13.04 & 158.66 & 405.47 & 80.03 & 2.60 & 0.50 & 1.77 \\
\hline & & (b) & 13.24 & 129.40 & 318.02 & 75.77 & 2.66 & 3.00 & 1.47 \\
\hline & & (c) & 13.83 & 128.32 & 316.45 & 75.38 & 2.55 & 1.00 & 1.96 \\
\hline \multirow{2}{*}{8} & \multirow{2}{*}{ HZ11-G12 } & (a) & 14.02 & 166.81 & 386.39 & 77.70 & 2.55 & 8.00 & 3.92 \\
\hline & & (b) & 13.83 & 141.76 & 339.83 & 77.00 & 2.56 & 10.00 & 9.81 \\
\hline \multirow{2}{*}{9} & \multirow{2}{*}{ HZ11-P14 } & (a) & 12.65 & 145.84 & 407.61 & 79.84 & 2.64 & 1.00 & 1.96 \\
\hline & & (d) & 13.53 & 93.87 & 215.31 & 68.08 & 2.23 & 3.00 & 3.92 \\
\hline $\operatorname{En~Az}$ & & & 12.65 & 62.70 & 173.89 & 63.29 & 2.23 & 0.00 & 1.47 \\
\hline En Fazla & & & 15.79 & 170.24 & 425.53 & 80.95 & 2.70 & 11.00 & 25.50 \\
\hline Ortalama & & & 13.90 & 129.11 & 321.28 & 74.65 & 2.57 & 3.96 & 4.87 \\
\hline Standart Sapma & & & 0.986 & 35.878 & 91.536 & 6.116 & 0.114 & 3.908 & 6.583 \\
\hline
\end{tabular}

Tablo 5. MLN sınıfındaki zeminlere ait laboratuvar sonuçları ve istatistiksel değerlendirme

\begin{tabular}{|c|c|c|c|c|c|c|c|c|c|}
\hline Örnek No & $\begin{array}{r}\text { Örnekl } \\
\text { Adı }\end{array}$ & & $\begin{array}{c}\gamma_{\mathbf{d}} \\
\left(\mathbf{k N} / \mathbf{m}^{3}\right)\end{array}$ & $\begin{array}{c}w \\
(\%)\end{array}$ & $\begin{array}{c}\mathrm{e} \\
(\%)\end{array}$ & $\begin{array}{c}\mathbf{n} \\
(\%)\end{array}$ & Gs & $\begin{array}{c}\phi \\
(\mathbf{o})\end{array}$ & $\begin{array}{c}\mathbf{c} \\
(\mathbf{k P a})\end{array}$ \\
\hline \multirow{3}{*}{4} & \multirow{3}{*}{ HZ11-P05 } & (a) & 17.85 & 37.75 & 110.00 & 51.79 & 2.76 & 0.50 & 15.69 \\
\hline & & (b) & 18.73 & 27.71 & 81.85 & 45.01 & 2.78 & 35.00 & 9.81 \\
\hline & & (c) & 18.04 & 30.44 & 94.66 & 48.43 & 2.75 & 13.00 & 13.73 \\
\hline \multirow{4}{*}{5} & \multirow{4}{*}{ HZ11-P06 } & (a) & 17.26 & 41.55 & 124.52 & 54.94 & 2.77 & 17.0 & 2.65 \\
\hline & & (b) & 18.44 & 32.81 & 95.08 & 48.57 & 2.76 & 12.00 & 7.36 \\
\hline & & (c) & 18.14 & 35.84 & 103.22 & 50.79 & 2.76 & 14.00 & 7.85 \\
\hline & & (d) & 17.75 & 29.96 & 92.62 & 48.05 & 2.68 & 10.00 & 4.90 \\
\hline \multirow{2}{*}{9} & \multirow{2}{*}{ HZ11-P14 } & (b) & 12.45 & 141.38 & 349.15 & 77.73 & 2.36 & 1.00 & 1.96 \\
\hline & & (c) & 12.75 & 127.87 & 347.62 & 77.66 & 2.62 & 2.00 & 1.96 \\
\hline & 12.45 & 27.71 & 81.85 & 45.01 & 2.36 & 0.50 & 1.96 \\
\hline \multicolumn{3}{|l|}{ En Fazla } & 18.73 & 141.38 & 349.15 & 77.73 & 2.78 & 35.00 & 15.69 \\
\hline \multicolumn{3}{|c|}{ Ortalama } & 16.82 & 56.15 & 155.41 & 55.89 & 2.69 & 11.61 & 7.32 \\
\hline \multicolumn{3}{|c|}{ Standart Sapma } & 2.431 & 44.823 & 110.06 & 12.668 & 0.1354 & 10.694 & 5.034 \\
\hline
\end{tabular}

Zeminlere ait jeomekanik özeliklerin derinlikle değişimleri incelendiğinde; en anlamlı ve belirgin değişimlerin doygun birim hacim ağırlı̆̆ ve boşluk oranı değerlerinde olduğunu görmek mümkündür. Her iki zemin sınıfında da doygun birim hacim ağırlık değerleri derinlikle orantılı olarak artış gösterirken, porozite ve boşluk oranı değerleri ise azalmaktadır. Bu değişim, zemin kalınlığının ve üstteki suyun yaptığı hidrostatik basıncın etkisiyle meydana gelen sıkılaşmadan kaynaklanmaktadır. Buna karşın, zeminlerin dayanım parametrelerinde (c ve $\phi$ ) derinliğe bağlı olarak herhangi bir değişimden bahsetmek mümkün değildir ve bu parametrelere ait değerler oldukça değişkendir. Ancak, MH ve MLN sınıfı zeminlere ait $\mathrm{c}$ ve $\phi$ değerleri karşılaştırıldığında; $\mathrm{MH}$ sınıfı zeminlerde ortalama c değeri $4.87 \mathrm{kPa}$ iken bu değer MLN sinıfı zeminlerde $7.32 \mathrm{kPa}$ 'dır. Ancak, $\phi$ değerlerinde durum farklıdır. MH sınıfı zeminlerin ortalama $\phi$ değeri $3.96^{\circ}$ gibi çok düşük bir değerde iken, bu değer MLN sinıfindaki zeminlerde $11.61^{\circ}$ 'dir ve $35^{\circ}$ 'ye kadar ulaşabilmektedir. Zemin içerisindeki iri dane (kum) oranının artışına bağlı olarak $\phi$ değeri artarken, $\mathrm{c}$ değerlerinde ise azalma görülmektedir. Zeminlerin özgül ağırlık değerleri de zemin sinıfindan etkilenmekte ve MH sinıfı 
zeminlerin özgül ağırlı değerlerinin MLN sınıfindaki zeminlere göre daha az olduğu görülmektedir (Tablo 4 ve 5). Aynı örneğin farklı seviyelerinde özgül ağırlık değerlerinde gözlenen ani azalmaların bu seviyelerdeki artan organik malzemeden kaynaklanabileceğini söylemek mümkündür.

\section{Hazar Gölü'ndeki sualtı (submarine) kütle hareketleri}

Kıta kenarları ve şelf alanları birkaç km kalınlığa ulaşabilen kalın sediman serilerini içeren önemli çökel alanlarıdır ve bu alanlarda biriken farklı özelliklerdeki sedimanlar zaman içerisinde çeşitli faktörlerin etkisi ile yenilmekte ve denizaltında kütle hareketleri oluşmaktadır. Karasal yamaçlarda olduğu gibi, denizaltında da malzeme üzerine etkiyen hareket ettirici kuvvetler malzemenin kesme dayanımından daha büyük olduğunda yenilme meydana gelmekte ve şelfteki zemin veya kaya kütlesi yer değiştirmektedir. Denizaltında oluşan kütle hareketlerinde malzemenin cinsi, dayanımı, zemin/kayanın siviya oran1, biriken malzemenin kalınlığı ve depremler gibi dinamik etkiler önemli bir rol oynamaktadır. Bu hareketler göller, kıyıya yakın alanlar, fiyortlar, aktif ve pasif kıta kenarları olmak üzere dünya çapında çok çeşitli ortamlarda meydana gelmektedir (Waneste vd., 2011). Denizaltı kütle hareketleri harekete ön hazırlık (pre-conditioning), hareketin tetiklenmesi (triggering) ve hareketin ilerlemesi veya bitişi (runout) olmak üzere üç aşamada gerçekleşmektedir (Locat, 2001; Canals vd., 2004). Hareketin bitiş aşaması genellikle, deniz tabanı altyapısına ve kayan malzemenin özelliğine bağlı olarak daha da alt bölümlere de ayrılabilmektedir (Bryn vd., 2005) (Şekil 5a). Bu konuda yapılan çalışmalarda (Middleton ve Hampton, 1973; Nardin vd., 1979; Hampton vd., 1996; Shanmugam, 2000; Mulder ve Alexander, 2001; Förster, 2011), su altında gelişen kütle hareketleri genel olarak blok ve moloz kaymaları, slumplar, moloz akmaları ve türbidit akıntıları şeklinde sınıflandırmıştır (Şekil 5b).

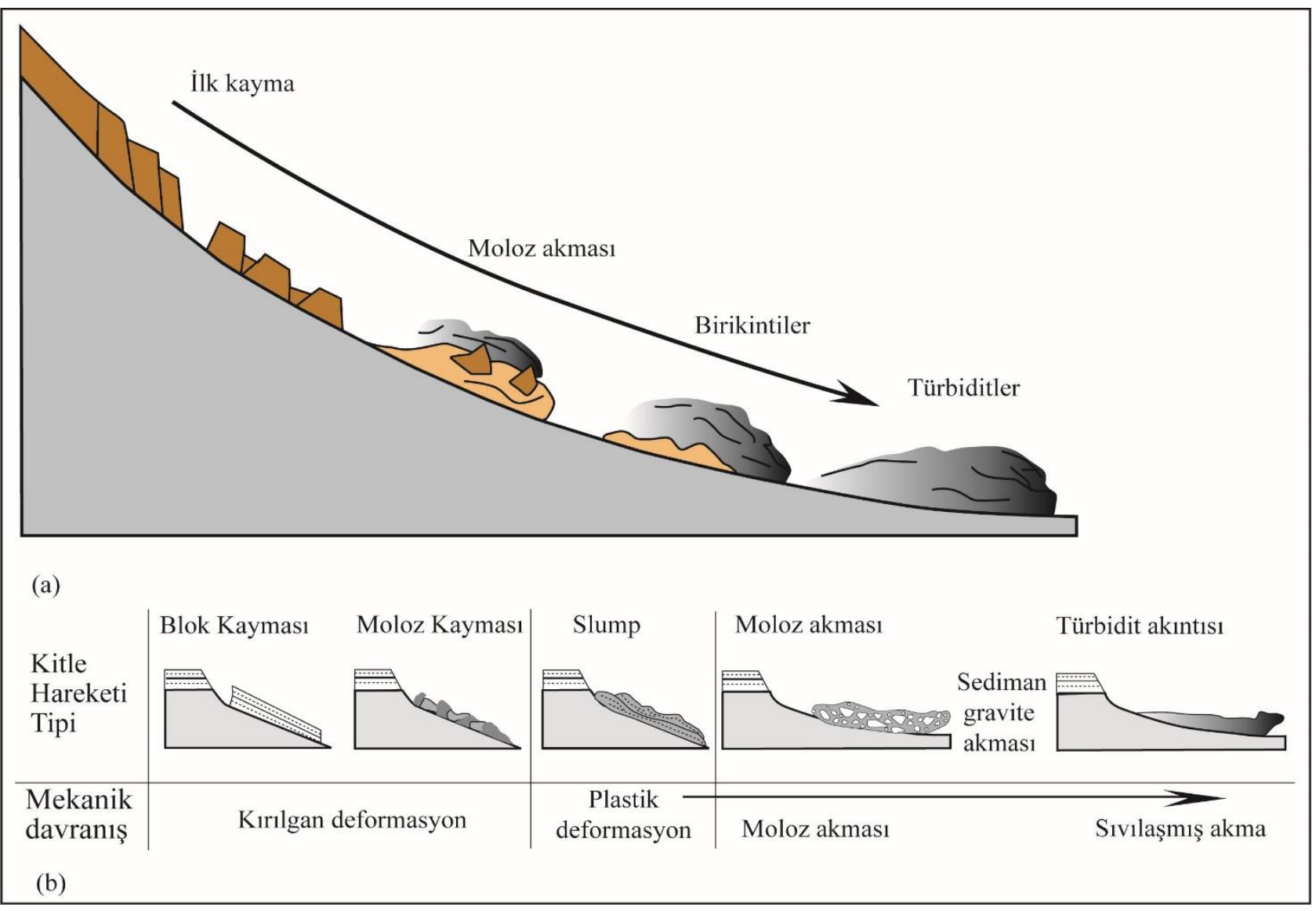

Şekil 5. (a) Denizaltı kütle hareketi gelişiminin şematik gösterimi (Bryn vd., 2005), (b) Denize taşınan sedimanların kütle hareket tipleri ve mekanik davranışları (Förster, 2011)

Kaymalar (slide); kütlelerin ve blokların düzlemsel bir kayma yüzeyi boyunca aşağı doğru hareket ettiği kayma tipidir. Kayan kütlede deformasyon gözlenmemekle birlikte kayma yüzeyinde küçük deformasyonlar gözlenebilmektedir. Kayan kütlenin özelliğine bağlı olarak blok kayması veya 
moloz kayması olarak adlandirılırlar. $\mathrm{Bu}$ hareketlerin oluşmasında biriken sedimanın kalınlığı ve türü önemli derecede rol oynarken, dinamik etkenler (deprem gibi) de hareketin oluşmasında etkili olabilmektedir. Dairesel yüzeyli kaymalar (slump); blok ve kütlelerin plastik deformasyon ile yamaç aşağı doğru kaydığı ve kaymanın konkav bir yüzey üzerinde gerçekleştiği hareket tipidir. Akmalar ise moloz akmasi ve türbiditik akmalar şeklinde oluşan hareket tipidir. Yamaç veya şelflerde biriken malzeme kendi ağırlı̆̆ının etkisiyle yamaç aşağı doğru şelf yüzeyi boyunca hızlı bir şekilde hareket eder. Akan malzemeye ve akış tipine bağl olarak moloz akması veya türbiditik akmalar olarak isimlendirilmektedirler (Maltman, 1994).

Denizaltı kütle hareketleri, tüm kıta kenarlarında ve tüm su derinliklerinde meydana gelen, Dünya üzerindeki en büyük doğa olayları arasındadır (Masson vd., 2006; Urlaub vd., 2013; Moscardelli ve Wood, 2016). Düşük eğimli yamaçlarda $\left(<2^{\circ}\right)$ ve büyük mesafelerde $(>1000 \mathrm{~km})$ meydana gelebildikleri gibi, hacim açısından, karadaki emsallerinden üç kat ve daha büyük olabilmektedirler (Hampton vd., 1996; Huhnerbach ve Masson, 2004; Korup, 2012). Kiyı toplulukları için önemli bir risk oluşturarak zarar veren tsunamileri oluşturabilmekte (Bondevik vd., 2005; Tappin vd., 2014) ve aynı zamanda, petrol ve doğal gaz üretimi için kullanılan deniz tabanı altyapısına veya küresel internet trafiğinin \%95'inden fazlasını taşıyan deniz tabanı telekomünikasyon kablolarına da zarar verebilmektedirler (Carter vd., 2012; Talling vd., 2014). Denizaltında meydana gelen bu kütle hareketlerinin nasıl tetiklendiğini açıklamak için çok çeşitli faktörler önerilmiştir (Locat ve Lee, 2002; Canals vd., 2004; Masson vd., 2006). Bunlar, heyelan malzemesinin jeolojik özellikleri, örneğin zayıf bir katmanın varlığı (Bryn vd., 2005; Locat vd., 2014), hızlı çökelti birikimi, aşırı basınç gelişimi (Dugan ve Flemings, 2000) ve aşırı dikleşme gibi geçici dış etkenleri içerir (AssierRzadkiewicz vd., 2000). Bu dış etkenlerden başka sismik yükleme (Piper vd., 1999), gaz hidrat ayrışması (Kennett vd., 2003; Maslin vd., 2004), firtına dalgası ve gelgit yüklemesi (Bea vd., 1983), buzul yüklemesi (Mulder ve Moran, 1995), sızıntı (Orange ve Breen, 1992), volkanik etkenler (Masson, 1996), tektonik hareketler ve insan faaliyetleri (Dan vd., 2007) de etkili olmaktadır.

$\mathrm{Bu}$ konuda yapılan çalışmalardaki en önemli gelişme, sismik yöntemler kullanılarak hareketin görüntülenmesi oluşturur ve en eski tam görüntüleme çalışmasında (Prior vd., 1982a) kıyıya yakın kütle hareketlerini görüntülemek için sığ suda yüzey taramalı sonar kullanılmıştır. Daha derin alanlarda ise yandan taramalı sonar sistemleri kullanılmış ve geniş alanlarda 50-100 m'lik yatay çözünürlükler elde edilerek, binlerce $\mathrm{km}^{2}$ 'lik alana sahip çok büyük kütle hareketlerinin birinci dereceden özelliklerinin haritalanması sağlanmıştır (Lipman vd., 1988; McAdoo vd., 2000; Collot vd., 2001). Ayrıca, denizaltı kütle hareketlerinin iç yapısına ait ayrıntıları ortaya çıkarmak ve sınırlı olmasına rağmen kalınlıklarını tahmin etmek için yüksek çözünürlüklü 2D sismik yansıma çalışmaları da yapılmıştır (Bugge vd., 1987; Locat ve Lee, 2002).

Sualtı kütle hareketi ile ilgili çalışmalarda esas amaç, bir veya birden fazla hareket tipinin özelliklerini tanımlamak ve bunlarla ilişkili süreçler ile bu süreci kontrol eden ve hareketi tetikleyen faktörler hakkında çıkarımlar yapmaktır. Bu amaca yönelik olarak ayrıntılı yüzey ve yeraltı çalışmaları yapılır. Morfolojik analizler bu çalışmaların en önemli aşamasını temsil ederler ve petrol endüstrisinde kullanılan 3 boyutlu sismik yansıma tekniğinin morfolojik analizlere de uygulanmasıyla bu konuda çok ciddi bir gelişme sağlanmıştır (FreyMartínez vd., 2006; Gee vd., 2007).

P-Cable gibi daha küçük ölçekli 3D sismik sistemler, deniz tabanında veya yakınındaki kütle hareketlerinin analizi için en uygun sistemlerdir ve $500 \mathrm{~m}$ den daha yukarıda çok yüksek çözünürlüğe (5-10 m) sahiptir (Berndt vd., 2012). 3D verilerin en büyük avantajı, hareket eden kütlenin özelliklerini yorumlayarak derinlemesine yüzeyler elde etme ve bu tür yüzeylerle ilişkili sismik özellikleri analiz etme yeteneğidir (Dalla Valle vd., 2013). 3D verilerden türetilen sismik özellikler, sıvı akış özelliklerini, kırılma ağlarını ve bunların heyelan deformasyonu ile ilişkisini analiz etmek için idealdir (Bünz vd., 2005). Denizaltında oluşan kütle hareketlerinin erozyonel bazal yüzeyinin 3 boyutlu sismik jeomorfolojisi, yerleşim sırasında hareketin yönünü tanımlayan çizgileri ortaya çıkarabilmektedir. Hareket etmiş eski ve gömülü bir kütlenin jeomorfolojisini hala deniz tabanındaymış gibi ortaya çıkarmak için 3D sismik verilerinin kullanması, kütle hareketlerinin süreçleri hakkındaki anlayışımızı önemli ölçüde artırmaya devam etmektedir (Mountjoy ve Micallef, 2018).

Sualtı kütle hareketleri konusunda yapılan tüm çalışmalar ve bu çalışmalara ait veriler incelendiğinde, oldukça zor gerçekleştirilen bu çalışmaların sualtında meydana gelen kütle hareketlerinin özellikleri ve bu hareketi tetikleyen faktörler konusunda yoğunlaştı̆̆ını görmek mümkündür. $\mathrm{Bu}$ veriler, hem bu kütle hareketlerini 
tanımlanması hem de bölgede geçmişte etkin olan deprem, volkanik aktivite gibi jeolojik etkenlerin ortaya çıkarılması açısından önem taşımaktadır.

Bu çalışmanın esas amacı Hazar Gölü çökellerinin mühendislik özeliklerinin belirlenmesi olmakla birlikte, Hazar Gölü’ne ait sığ-sismik profillerde göl yamaçlarında sualtında meydana gelmiş olan kütle hareketlerinin varlığı, bu hareketlerin de araştırılmasını, hareket tipleri, oluşum süreci ile hareketlerin oluşumunda etkin olan faktörlerin ortaya konulmasını gerekli kılmaktadır. Ancak, bu tür çalışmalarda daha detaylı incelemelere ve verilere gereksinim vardır. Şu an için bu kütle hareketlerinin oluşum mekanizması ve nedenlerini net olarak ortaya koyabilecek yeterli veri mevcut değildir. Ancak, eldeki veriler yardımıyla belirlenen kütle hareketlerinin tipi, hangi tür zeminler içerisinde geliştiği ve gelişiminde hangi faktörlerin etkili olduğu konusunda yorum yapmak mümkündür. $\mathrm{Bu}$ kütle hareketlerini tanımlamak ve sonraki y1llar için bir veri tabanı oluşturmak amacıyla kütle hareketlerinin gözlendiği 4, 26-1, 6, 20-3 ve 19-4 nolu sismik profillere ait kesitler üzerinde yoğunlaşılmıştır. $\mathrm{Bu}$ kesitler incelendiğinde, yüksek eğime sahip yamaçlarda çökel kalınlığ çok az $(<3 \mathrm{~m})$ iken, daha az eğimli yamaçlarda çökel kalınlığı 10 m'ye kadar ulaşabildiği görülmektedir. Göl yamaçlarının morfolojisinin oluşumunda ve buna bağll olarak yamaçların eğimini belirleyen en önemli faktör, Hazar Gölü'nünden geçen DAFZ'ye ait düşey bileşeni de olan doğrultu atımlı faylardır. Bu faylar özellikle gölün güney yamaçlarının dikleşmesinde ana rölü oynamaktadırlar. Nitekim bölgeye ait jeoloji haritası (Şekil 2) ve güney yamaçlara ait sismik profiller (Şekil 6) incelendiğinde, bu yamacın düşey veya düşey bileşeni olan doğrultu atıml faylar tarafından kontrol edildiği görülmektedir. Böylece, eğimin yüksek olduğu güney yamaçlarda zeminin dayanımı çok düşük olduğundan birikme olmamakta ve biriken zeminler de kendi ağırlığı ile göl tabanına doğru akmaktadır. Hazar Gölü'nün hem kuzey hem de güney yamaçlarında oluşmuş sualtı kütle hareketleri de çökel kalınlığının fazla, eğimin ise nispeten daha düşük olduğu yamaçlarda daha belirgin olarak gözlenmektedir (Şekil 6, 7 ve 8). Bu kütle hareketleri Holosen yaşlı sıkılaşmamış, boşluk oranı oldukça yüksek ve yüksek plastisiteli siltlerde (Tablo 3 ve 4) meydana gelmiştir ve genel olarak plastik deformasyonunda eşlik ettiği dairesel yüzeyli kayma (slup) tipi kütle hareketleridir. Sadece 26-1 nolu profile ait kesitte az da olsa plastik deformasyonun da gözlendiği moloz akmas1 şeklindedir (Şekil 6b). Slump tipi plastik deformasyonun gözlendiği hareketler, kütlelerin daha çok kendi ağırlığı ile yamaç aşağı kaydığı, plastik deformasyonların ve konkav şekilli kayma yüzeylerinin görülebildiği kütle hareketleridir ve Hazar Gölü kuzey ve güney yamaçlarında gözlenen kütle hareketleri bu tanımlara tamamen uymaktadır. Hazar Gölü yamaçlarında biriken ve kütle hareketlerinin gözlendiği malzemenin dayanım değerlerine bakıldığında (Tablo 5), oldukça düşük dayanıma sahip bu malzemenin kayabilmesi için kendi ağırlığ 1 yeterli olacaktır. Genel olarak malzemenin kendi ağırlığının etkisiyle oluşan bu kaymaları DAFZ'de meydana gelen depremler de kolaylaştırmaktadır. 


\section{GD}
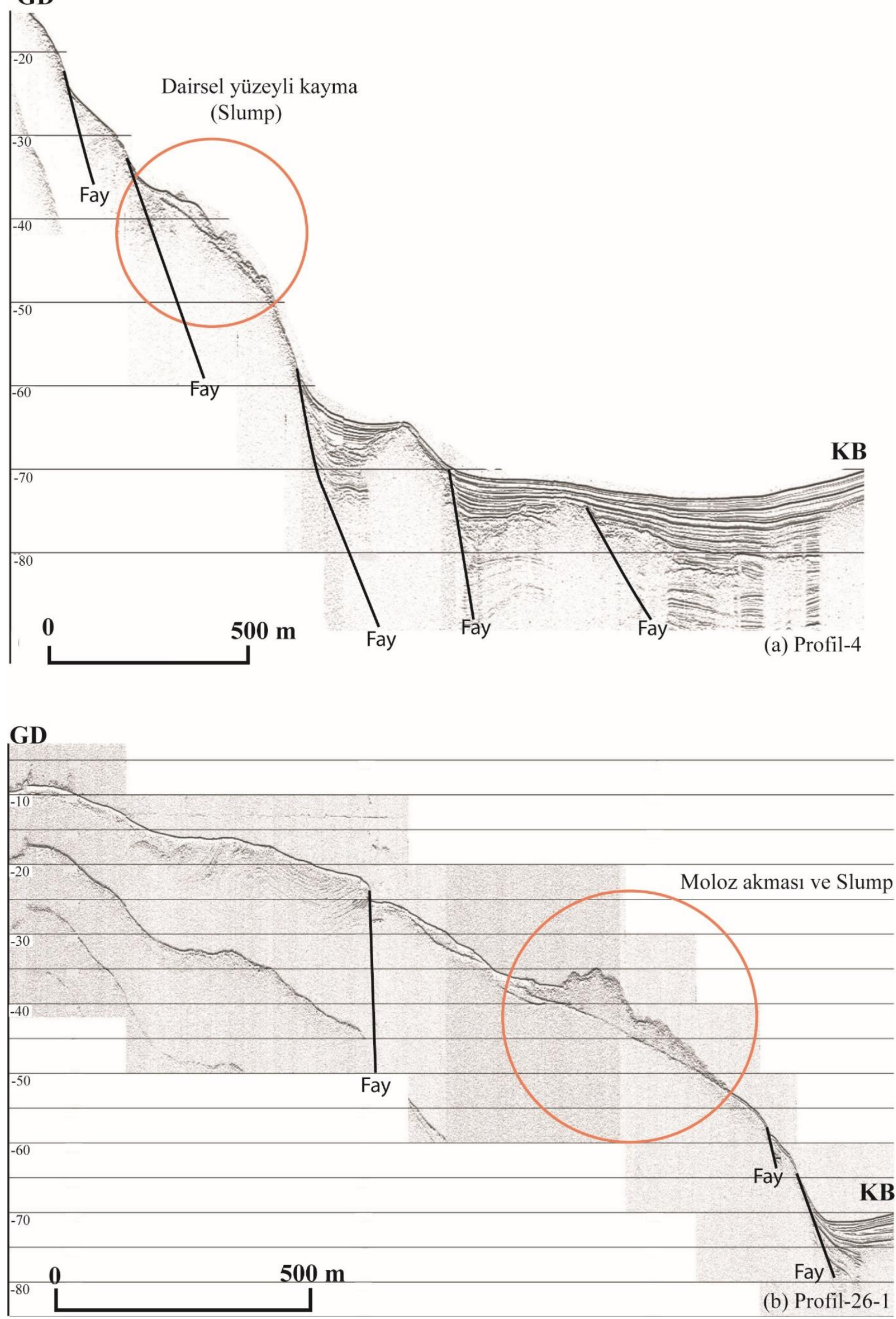

Şekil 6. Hazar Gölü güney yamaçlarında gözlenen sualtı kütle hareketleri (a) 4 nolu profile ait kesit, (b) 26-1 nolu profile ait kesit (TÜBİTAK, 2014) 


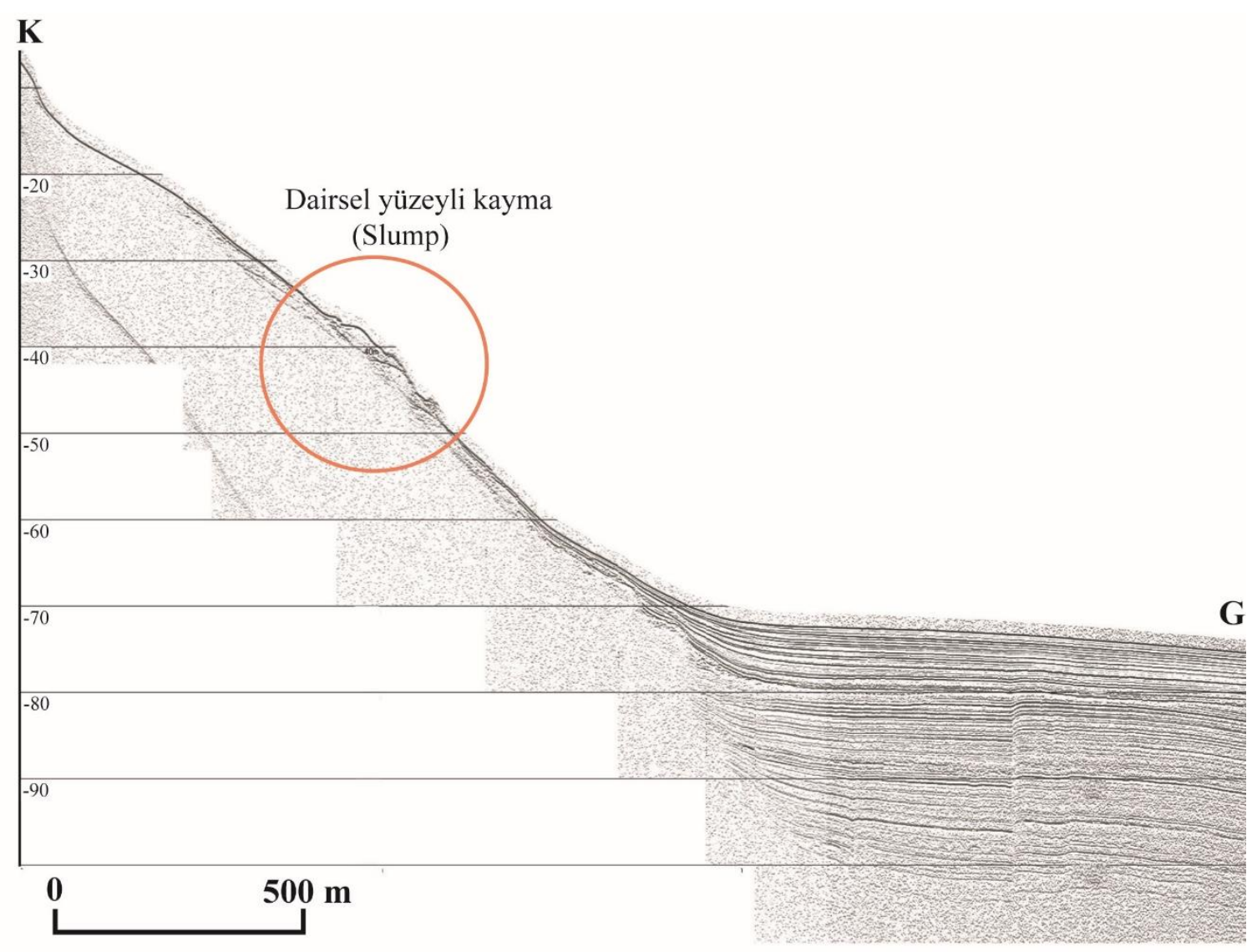

(a) Profil-6

\section{B}

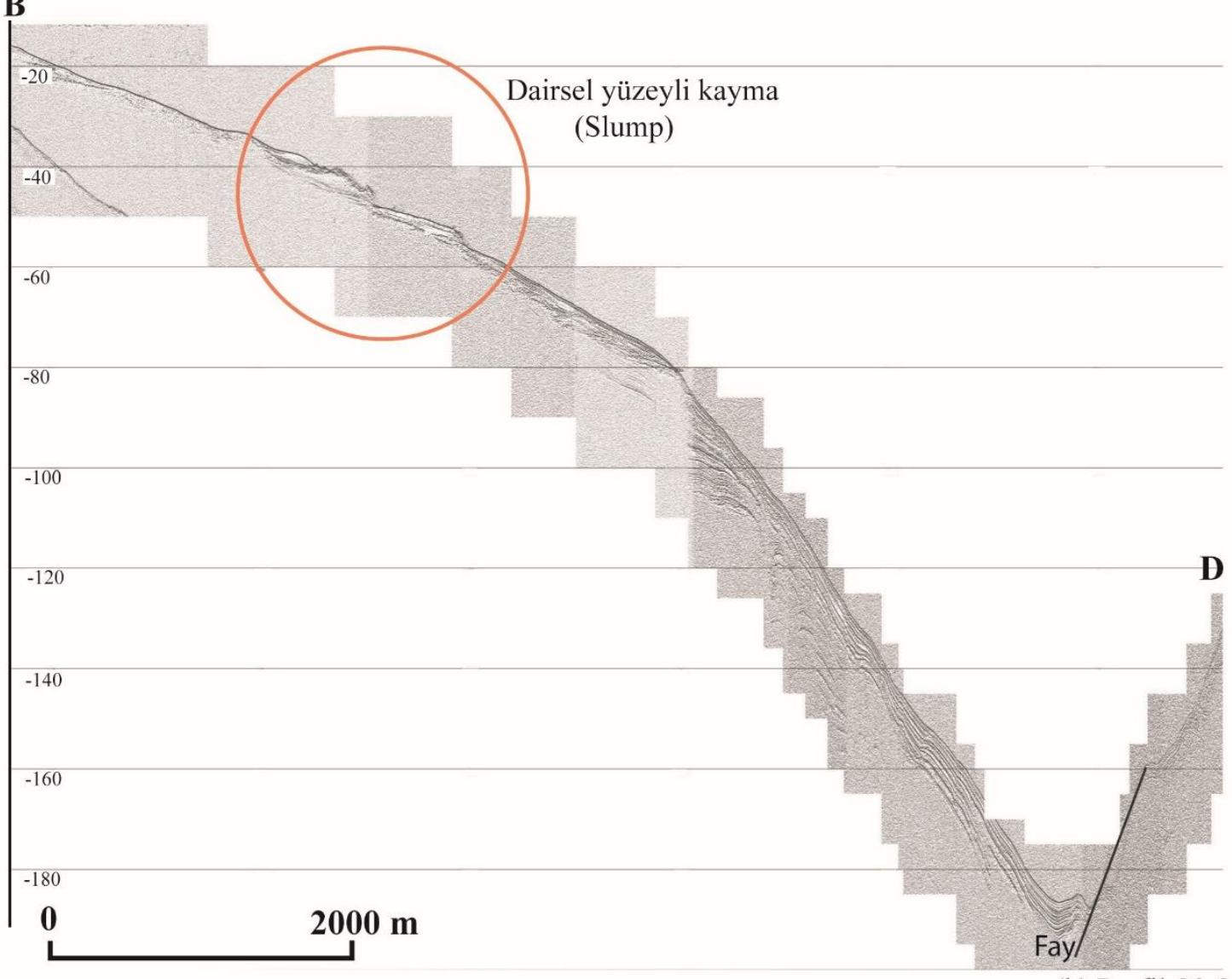

(b) Profil-20-3

Şekil 7. Hazar Gölü kuzey yamaçlarında gözlenen sualtı kütle hareketleri (a) 6 nolu profile ait kesit, (b) 20-3 nolu profile ait kesit (TÜBİTAK, 2014) 


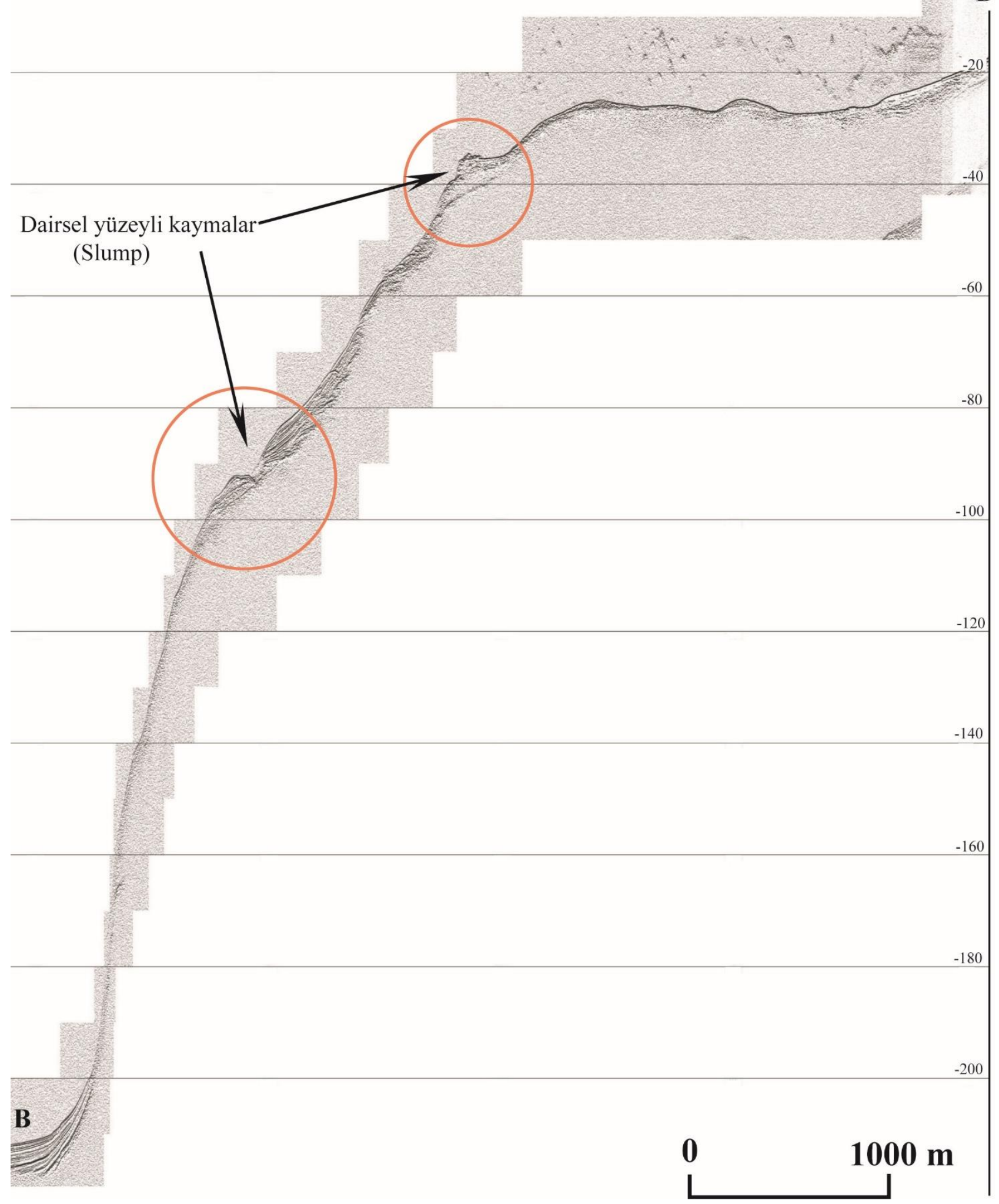

Şekil 8. Hazar Gölü kuzey yamaçlarında 19-4 nolu profile ait kesitte gözlenen sualtı kütle hareketleri (TÜBİTAK, 2014)

\section{Sonuçlar}

$\mathrm{Bu}$ çalışmadan elde edilen sonuçları şu şekilde siralamak mümkündür;
1. Hazar Gölü yamaçlarında birikmiş olan zeminden derlenen örneklerde yapılan zemin sınıflamalarına göre gölün orta kesimlerinden alınan 1, 2, 3, 6, 7 ve 8 nolu örneklerin $\mathrm{MH}$ sinıfinda; 4 ve 5 nolu örneklerin ise MLN sınıfinda olduğu belirlenmiştir. 9 nolu örneğin 
ise alt ve üst seviyeleri MH sınıfinda iken, ara seviyeler MLN sınıfındadır. Çökellerin zemin sinıfi ile örnekleme noktaları arasinda bir ilişkinin varlı̆̆ 1 dikkat çekmektedir. Hazar Gölü'nün batısındaki Kürk Çayı'nın göle giriş yaptığı alandan alınan örnekler MLN sınıfinda iken, kıyıdan uzakta ve gölün orta kesiminden alınan örneklerin zemin sinıfi MH olarak belirlenmiştir. Kürk Çayı'nın taşıdığı çökellerden iri daneli olanlar, çayın göle giriş yaptığı alanlarda hemen çökelmekte, böylece bu alandan alınan örneklerdeki kum oranı daha fazla ve zemin sinıfi ise MLN olmaktadır. Daha ince daneler ise gölün orta kesimlerine kadar süspansiyon halinde ulaşarak çökelmektedir ve bu nedenle bu alanlardan alınan örneklerin zemin sınıfı MH'dır.

2. MH sinifi zeminlerin doygun birim hacim ağırlığ 1 12.65-15.79 kN/m³ , su içeriği \% 62.70170.24, boşluk oranı \% 173.89-425.53, porozitesi \% 63.29-80.95, özgül ağırlı̆̆ ise 2.23-2.70 arasında değișmektedir. Zemin örneklerinin oldukça düşük kohezyon ve içsel sürtünme açısına sahiptir. Kohezyon değeri en fazla $25.50 \mathrm{kPa}$ iken, $\phi$ değerleri $0^{\circ}-11^{\circ}$ arasindadir.

3. MLN sinıfındaki zeminin doygun birim hacim ağırlığı $12.45-18.73 \mathrm{kN} / \mathrm{m}^{3}$, su içeriği \% 27.71141.38, boşluk oranı \% 81.85-349.15, porozitesi \% 45.01-77.73 ve özgül ağırlığ 1 ise 2.36-2.78 değerleri arasındadır. MLN sınıfindaki zeminlerin maksimum $\mathrm{c}$ değeri $15.69 \mathrm{kPa}, \phi$ değeri ise $35^{\circ}$ ' dir ve MH sınıfi zemine göre daha düşük c, daha yüksek $\phi$ değerlerine sahiptir. Zemin içerisindeki kum ve silt oranının artışına bağlı olarak $\phi$ değeri artarken, c değerlerinde ise azalma görülmektedir.

4. Zeminlerin doygun birim hacim ağırlık değerleri derinlik arttıkça artmakta, porozite ve boşluk oranı değerleri ise azalmaktadır. $\mathrm{Bu}$ değişim, zemin kalınlığının ve üstteki suyun yaptığı hidrostatik basıncın etkisiyle meydana gelen sıkılaşmadan kaynaklanmaktadır. Ancak, c ve $\phi$ değerleri ile derinlik arasında anlamlı bir ilişki yoktur. Bu değerler zeminin içerdiği danelerin boyutuna bağlı olarak artmakta veya azalabilmektedir. MH sinifi zeminlerin ortalama $\phi$ değeri $3.96^{\circ}$ iken bu değer MLN sınıfındaki zeminlerde $11.61^{\circ}$ ye kadar ulaşabilmektedir.

5. MH sınıfı zeminlerin özgül ağırlık değerleri MLN sınıfındaki zeminlere göre daha azdır ve aynı örneğin farklı seviyelerinde özgül ağırlık değerlerinde gözlenen ani azalmalar meydana gelmektedir. $\mathrm{Bu}$ azalmaların artan organik malzemeden kaynaklandığını söylemek mümkündür.

6. Hazar Gölü'ne ait sığ-sismik kesitlere göre, gölün yüksek eğime sahip özellikle güney ve doğu yamaçlarındaki çökel kalınlığı maksimum $3 \mathrm{~m}$ iken, daha az eğimli kuzey ve batı yamaçlardaki çökellerin 10 m'ye kadar ulaşabilmektedir. Bunun nedeni, zeminin dayanımının çok düşük olması nedeniyle eğimin yüksek olduğu yamaçlarda zeminin kendi ağırlığı ile göl tabanına doğru akması ve nispeten yüksek eğimli bu yamaçlarda zeminin birikmesinin sınırlı olmasıdır. Hazar Gölü'nün kuzey ve güney yamaçlarındaki sualtı kütle hareketleri çökel kalınlığının fazla, eğimin ise nispeten daha düşük olduğu yamaçlarda gözlenmektedir.

7. Holosen yaşlı sıkılaşmamış, boşluk oranı oldukça yüksek ve MH sınıfı bu çökellerde gelişmiş olan sualtı kütle hareketleri genel olarak plastik deformasyonunda eşlik ettiği dairesel yüzeyli kayma (slup) tipi hareketlerdir. $\mathrm{Bu}$ hareket tipinde kütleler kendi ağırlığı ile yamaç aşağı kaymakta, plastik deformasyonların ve konkav şekilli kayma yüzeyleri görülebilmektedir. Hazar Gölü yamaçlarında biriken çökellerin çok düşük dayanıma sahip olması nedeniyle bu malzemenin kendi ağırlığının etkisiyle rahatlıkla aşağı doğru kayabilecektir. Bu kütle hareketlerinin olușumunda DAFZ'de meydana gelen depremlerin de etkisi kaçınılmazdır. DAFZ'de meydana gelen depremlerin, göl yamaçlarındaki kütle hareketlerine olan etkilerinin belirlenebilmesi, sismik yüklerin dikkate alındığı geriye dönük duraylılık analizlerinin yapılması ve bölgede oluşan depremler sonrasinda yapilacak sismik çalışmalar ile oluşan kütle hareketleri görüntülenerek elde edilen sonuçların deneştirilmesi ile mümkün olabilecektir.

\section{Teșekkür / Katkı Belirtme}

Bu çalışma, Fırat Üniversitesi, Bilimsel Araştırma Projeleri Koordinasyon Birimi (FÜBAP) tarafindan MF.12.24 numaral1 proje ile maddi olarak desteklenmiştir. Makalenin inceleme ve değerlendirme aşamasında yapmış oldukları katkılardan dolayı editör ve hakemlere teşekkür ederiz. 


\section{Kaynaklar}

Ai, F., Förster, A., Stegmann, S. ve Kopf, A. (2014). Geotechnical characteristics and slope stability analysis of the deeper slope of the Ligurian Margin, Southern France. The Beijing Landslide Forum (pp.549-555). Beijing. https://doi.org/10.1007/978-3-319-04996-0_84.

Aksoy, E., İnceöz, M. ve Koçyiğit, A. (2007). Lake Hazar Basin: a negative flower structure on the East Anatolian Fault System (EAFS), SE Turkey. Turkish Journal of Earth Sciences, 16, 319-338.

Alpar, B. (1999). Underwater signatures of the Kocaeli earthquake of 17 August 1999 in Turkey. Turkish Journal of Marine Sciences, 5, 111-130.

Arpat, E. ve Şaroğlu, F. (1972). Doğu Anadolu Fayı ile ilgili gözlemler ve düşünceler. MTA Enstitüsü Dergisi, 78, 44-50, Ankara.

Aslan Y. (2013). Hazar Gölü (Elazığ) çökellerinin mühendislik özellikleri. Yüksek Lisans Tezi, Frrat Üniversitesi, Fen Bilimleri Enstitüsü, Elazığ.

Assier-Rzadkiewicz, S., Heinrich, P., Sabatier, P.C., Savoye, B. ve Bourillet, J.F. (2000). Numerical modelling of a landslide-generated tsunami: the 1979 Nice event. Pure Applied Geophysics, 157, 1717-1727, https://doi.org/10.1007/PL00001057.

ASTM D 422-63 (2007). Standard Test Method for Particle-Size Analysis of Soils, West Conshohocken, PA.

ASTM D4531-86 (2010). Standard test methods for bulk density of peat and peat products, in Annual Book of ASTM Standards. West Conshohocken: ASTM International.

ASTM D3080/D3080M (2011). Standart Test Method for Direct Shear Test of Soils Under Consolidated Drained Conditions, in: Annual Book of ASTM Standards; 04.08, West Conshohocken, 347-352.

ASTM D854-02 (2014). Standard Test Method for Specific Gravity of Soils, in: Annual Book of ASTM Standards, 04.08, West Conshohocken, 93-9.

ASTM 2487 (2017). Standard Practice for Classification of Soils for Engineering Purposes (Unified Soil Classification System) in: Annual Book ASTM Standarts, 04.08, West Conshohocken.

ASTM D4318 (2017). Standard Test Method for Liquid Limit, Plastic Limit and Plasticity Index of Soils, in: Annual Book ASTM Standarts, 04.08, West Conshohocken, 582-595.

ASTM D2216 (2019). Standard test method for laboratory determination of water (moisture) content of soil and rock by mass obsolete, in:
Annual Book ASTM Standarts, 04.08, West Conshohocken.

Auffret, G.A., Auzende, J.M., Gennesseaux, M., Monti, S., Pastouret, L., Pautot, G. ve Vanney, J. (1982). Recent mass wasting processes on the Provencal Margin (Western Mediterranean). Saxov, S. and Nieuwenhuis, J.K. (Ed.), Marine Slides and Other Mass Movements, (pp. 53-58). New York: Springer.

Bardet, J.P. (1997). Experimental Soil Mechanics (1st ed.), New Jersey: Pearson Education.

Başaran, S. (2002). Marmara Denizi'nde kütle hareketi kökenli depoların sedimentolojik özellikleri. Yüksek Lisans Tezi, İstanbul Üniversitesi Deniz Bilimleri ve İşletmeciliği Enstitüsü, İstanbul.

Bea, R.G., Wright, S.G., Sircar, P. ve Niedoroda, A. (1983). Wave-induced slides in south pass block 70, Mississippi Delta. Journal of Geotechnical Engineering, 109, 619-644, https://doi.org/10.1061/(ASCE)07339410(1983)109:4(619).

Berndt, C., Costa, S., Canals, M., Camerlenghi, A., De Mol, B. ve Saunders, M. (2012). Repeated slope failure linked to fluid migration: the ANA submarine landslide complex, Eivissa channel, Western Mediterranean Sea. Earth Planetary Science Letters, 319-320, 65-74, https://doi.org/10.1016/j.epsl.2011.11.045.

Beuselinck, L., Govers, G., Poesen, J., Degraer, G. ve Froyen, L. (1998). Grain-size analysis by laser diffractometry: comparison with the sieve-pipette method. Catena, 32, 193-208.

Bondevik, S., Løvholt, F., Harbitz, C.B., Mangerud, J., Dawson, A. ve Svendsen, J.I. (2005). The Storegga Slide tsunami-comparing field observations with numerical simulations. Marine and Petroleum Geology, 22(1-2), 195-208, https://doi.org/10.1016/j.marpetgeo.2004.10.003.

Bryn, P., Berg, K., Forsberg, C.F., Solheim, A. ve Kvalstad, T.J. (2005). Explaining the Storegga Slide. Marine and Petroleum Geology, 22(1-2), 11-19, https://doi.org/10.1016/j.marpetgeo.2004.12.003.

Bugge, T., Befring, S., Belderson, R.H., Eidvin, T., Jansen, E., Kenyon, N., Holtedahl, H. ve Sejrup, H.P. (1987). A giant three-stage submarine slide off Norway. Geo-Marine Letters, 7(4), 191-198, https://doi.org/10.1007/BF02242771.

Bünz, S., Mienert, J., Bryn, P. ve Berg, K. (2005). Fluid flow impact on slope failure from 3D seismic data: a case study in the Storegga Slide. Basin Research, 17(1):109-122, https://doi.org/10.1111/j.13652117.2005.00256.x. 
Canals, M., Lastras, G., Urgeles, R., Casamor, J.L., Mienert, J., Catdaneo, A., De Batist, M., Haflidason, H., Imbo, Y., Laberg, J.S., Locat, J., Long, D., Longva, O., Masson, D.G., Sultan, N., Trincardi, F. ve Bryn, P. (2004). Slope failure dynamics and impacts from seafloor and shallow sub-seafloor geophysical data: case studies from the COSTA Project. Marine Geology, 213(1-4), 9-72, https://doi.org/10.1016/j.margeo.2004.10.001.

Canpolat, Ö., Eriş, K.K. ve Akkoyun, E.Ö. (2020). Determining the concentration level of some elements caused by geological period in the sediments of Lake Hazar. Turkish Journal of Agriculture-Food Science and Technology, 8(4), 1001-1011,

https://doi.org/10.24925/turjaf.v8i4.10011011.3319.

Carter. L., Milliman, J.D., Talling, P.J., Gavey, R. ve Wynn, R.B. (2012). Near-synchronous and delayed initiation of long run-out submarine sediment flows from a record-breaking river flood, offshore Taiwan. Geophysical Research Letters, 39, L12603, https://doi.org/10.1029/2012GL051172.

Cochonat, P., Bourillet, J.F., Savoye, B. ve Dodd, L. (1993). Geotechnical characteristics and instability of submarine slope sediments, the Nice slope (N-W Mediterranean Sea). Marine Georesources \& Geotechnology, 11(2), 131-151, https://doi.org/10.1080/10641199309379912.

Collot, J-Y., Lewis, K., Lamarche, G. ve Lallemand, S. (2001). The giant Ruatoria debris avalanche on thenorthern Hikurangi margin, New Zealand: result of oblique seamount subduction, Journal Geophysical Research, 106(B9), 19271-19297, https://doi.org/10.1029/2001JB900004.

Çağatay, M.N., Algan, O., Sakinc, M., Eastoe, C., Tolun, L., Balkis, N., Ongan, D. ve Caner, H. (1999). A Mid-Late Holocene sapropelik sediment unit from the southern Marmara shelf and its palaeoceanographic significance. Quaternary Geology Reviews, 18, 531-540, https://doi.org/10.1016/S0277-3791(98)00094-8.

Çetin, H., Güneyli, H. ve Mayer, L. (2003). Paleoseismology of the Palu-Lake Hazar segment of the East Anatolian Fault Zone, Turkey. Tectonophysics, 374(3-4), 163-197, https://doi.org/10.1016/j.tecto.2003.08.003.

Dalla Valle, G., Gamberi, F., Rocchini, P., Minisini, D., Errera, A., Baglioni, L. ve Trincardi, F. (2013). 3D seismic geomorphology of mass transport complexes in a foredeep basin: examples from the Pleistocene of the central adriatic basin (Mediterranean Sea). Sedimentary Geology 294, 127-141, https://doi.org/10.1016/j.sedgeo.2013.05.012.
Dan-Unterseh, G., Sultan, N. ve Savoye, B. (2007). The 1979 Nice harbour catastrophe revisited: trigger mechanism inferred from geotechnical measurements and numerical modelling. Marine Geology, 245(1-4), 40-64, https://doi.org/10.1016/j.margeo.2007.06.011.

Dugan, B. ve Flemings, P.B. (2000). Overpressure and fluid flow in the New Jersey continental slope: implications for slope failure and cold seeps. Science 289(5477), 288-291, https://doi.org/10.1126/science.289.5477.288.

Duman, T.Y. ve Emre, Ö. (2013). The East Anatolian Fault: Geometry, Segmentation and Jog Characteristics. Geological Society, London, Special Publications published online, 372,495529, https://doi.org/10.1144/SP372.14.

Dunne, L.A. ve Hempton, M.R., (1984). Deltaic sedimentation in the Lake Hazar pull-apart basin, south-eastern Turkey. Sedimentology, 31(3), 401412, https://doi.org/10.1111/j.13653091.1984.tb00868.x.

Elverhøi, A., Norem, H., Anderson, E.S., Dowdeswell, J.A., Fossen, I., Haflidason, H., Kenyon, N.H., Laberg, J.S., King, E.L., Sejrup, H.P., Solheim, A. ve Vorren, T., (1997). On the origin and flow behavior of submarine slides on deep-sea fans along the orwegian-Barents Sea continental magrin. Geo-Marine Letters, 17, 119-125, https://doi.org/10.1007/s003670050016.

Eriş, K.K. (2013). Late Pleistocene-Holocene sedimentary records of climate and lake-level changes in Lake Hazar, eastern Anatolia. Turkey, Quaternary International, 302, 123-134, https://doi.org/10.1016/j.quaint.2012.12.024.

Eriş, K.K., Ryan, W.B.F., Çağatay, M.N., Sancar, U., Lericolais, G., Ménot, G. ve Bard, E. (2007). The timing and evolution of the post-glacial transgression across the Sea of Marmara shelf south of Istanbul. Marine Geology, 243(1-4), 5776 ,

https://doi.org/10.1016/j.margeo.2007.04.010.

Eriş, K.K., Akçer Ön, S., Çağatay, M.N., Ülgen, U.B., Ön, Z.B., Gürocak, Z., Arslan, T.N., Bal Akkoca, D., Damc1, E., İnceöz, M. ve Öztekin Okan, Ö. (2018a). Late Pleistocene to Holocene paleoenvironmental evolution of Lake Hazar, Eastern Anatolia, Turkey. Quaternary International, 436, 4-16, https://doi.org/10.1016/j.quaint.2017.09.027.

Eriş, K.K., Arslan, T.N. ve Sabuncu, A. (2018b). Influences of climate and tectonic on the middle to late Holocene deltaic sedimentation in Lake Hazar, Eastern Turkey. Arabian Journal for Science and Engineering, 43, 3685-3697, https://doi.org/10.1007/s13369-017-3021-1. 
Förster, A. (2011). Geotechnical measurements to characterise slope sediments and to identify landslide mechanisms and their impact on ecosystems, Doctoral Thesis, Faculty of Geosciences of Bremen University.

Förster, A., Stegmann, S., Meyer, M., Strozyk, F., Krastel, S. ve Kopf, A. (2007). Geotechnical investigations to characterise landslide-prone slope sediments in the Cretan Sea (Northern Crete). International Conference and $97^{\text {th }}$ Annual Meeting of the Geologische Vereinigung (pp.149). Bremen.

Förster, A., Strasser, M., Strozyk, F., Spagnoli, G., Stegmann, S. ve Kopf, A. (2008). Characterization of landslide-prone slope sediments in the Cretan sea (eastern Mediterranean), 33 ${ }^{\text {rd }}$ International Geological Congress (pp.151), Oslo.

Förster, A., Spieß, V., Kopf, A.J. ve Dennielou, B., (2010a). Mass wasting dynamics at the deeper slope of the Ligurian Margin (Southern France). Mosher, DC., Shipp, C., Moscardelli, L., Chaytor, J., Baxter, C., Lee, H., and Urgeles, R. (Ed.), Submarine Mass movements and Their Consequences (pp. 67-77). New York; London: Springer.

Förster, A., Ellis, R.G., Henrich, R., Krastel, S. ve Kopf, A.J. (2010b). Geotechnical characterization and strain analyses of sediment in the Mauritania Slide Complex, NW-Africa. Marine and Petroleum Geology, 27(6), 1175-1189, https://doi.org/10.1016/j.marpetgeo.2010.02.013.

Frey-Martínez, J., Cartwright, J. ve James, D. (2006). Frontally confined versus frontally emergent submarine landslides: a 3D seismic characterisation. Marine and Petroleum Geology, 23(5), 585-604, https://doi.org/10.1016/j.marpetgeo.2006.04.002.

Gazioglu, C., Yucel, Z.Y. ve Dogan, E., (2005). Morphological features of major submarine landslides of Marmara Sea using multibeam data. Journal of Coastal Research, 21(4), 664-673, https://doi.org/10.2112/03-0060.1.

Gee, M., Uy H.S., Warren, J.K., Morley, C.K. ve Lambiase, J.J. (2007). The Brunei slide: a giant submarine landslide on the North West borneo margin revealed by $3 \mathrm{D}$ seismic data. Marine Geology, 246(1), 9-23, https://doi.org/10.1016/j.margeo.2007.07.009

Gokceoglu, C., Tunusluoglu, M.C., Gorum, T., Tur, H., Gokasan, E., Tekkeli, A.B., Batuk, F. ve Alp, H. (2009). Description of dynamics of the Tuzla Landslide and its implications for further landslides in the northern slope and shelf of the Cinarcik Basin (Marmara Sea, Turkey).
Engineering Geology, 106(3-4), 133-153, https://doi.org/10.1016/j.enggeo.2009.02.007.

Gorur, N., Ozeren, M.S., Cagatay, M.N. ve Sengor, A.M.C. (2008). Northern margin of the Cinarcik Basin: An unstable submarine fault scarp prone to mass movements. 61th Geological Congress of Turkiye (pp. 219-220). Ankara.

Gürocak, Z. (1993). Sivrice (Elazığ) Çevresinin Jeolojisi, Yüksek Lisans Tezi, Frrat Üniversitesi, Fen Bilimleri Enstitüsü, Elazığg.

Hampton, M.A., Lee, H.J. ve Locat, J. (1996). Submarine landslides. Reviews of Geophysics, 34(1), 33-59, https://doi.org/10.1029/95RG03287.

Hempton, M.R. (1984). Results of detailed mapping near Lake Hazar (Eastern Taurus Mountains). Geology of Taurus Belts, 229-235.

Hempton, M.R. (1985). Structure and deformation history of the Bitlis Suture Zone near Lake Hazar southeastern Turkey. The Geological Society of America Bulletin, 96(2), 233-243, https://doi.org/10.1130/00167606(1985)96<233:SADHOT>2.0.CO;2.

Hempton, M.R., Dunne, L.A. ve Dewey, J.F. (1983). Sedimentation in an active strike-slip basin, South-eastern Turkey, Journal of Geology, 91(4), 401-412, https://doi.org/10.1086/628786.

Herece, E. ve Akay, E. (1992). Karlıova-Çelikhan arasında Doğu Anadolu Fayı. Türkiye 9. Petrol Kongresi Bildirileri, 361-372.

Huntington, E. (1902). The valley of the upper Euphrates River and its people. Geological Society of America Bulletin, 34, 301-318.

Hühnerbach, V. ve Masson, D.G. (2004). Landslides in the North Atlantic and its adjacent seas:an analysis of theirmorphology, setting and behaviour. Marine Geology, 213(1-4), 343-362, https://doi.org/10.1016/j.margeo.2004.10.013.

Imran, J., Harff, P. ve Parker, G. (2001a). A numerical model of submarine debris flow with graphical user interface. Computers \& Geosciences, 27(6), 717-729, https://doi.org/10.1016/S00983004(00)00124-2.

Imran, J., Parker, G., Locat, J. ve Lee, H. (2001b). 1D Numerical model of muddy subaqueous and subaerial debris flows. Journal of Hydraulic Engineering, 127(11), 959-968, https://doi.org/10.1061/(ASCE)07339429(2001)127:11(959).

Ioualalen, M., Migeon, S. ve Sardoux, O. (2010). Landslide tsunami vulnerability in the Ligurian Sea: case study of the 1979 October 16 Nice international airport submarine landslide and of 
identified geological mass failures. Geophysical Journal International, 181(2), 724-740, https://doi.org/10.1111/j.1365-

246X.2010.04572.x.

Jackson, J.A. ve McKenzie, D. (1984). Active tectonic of the Alpine-Himalayan belt between western Turkey and Pakistan. Geophysical Journal of the Royal Astronomical Society, 77, 185-264.

Kaya, A. (1993). Gezin-Maden (Elazı̆g) çevresinde jeolojik araştırmalar, Yüksek Lisans Tezi, Fırat Üniversitesi, Fen Bilimleri Enstitüsü, Elazığg.

Kaya, A. (2004). Gezin (Maden-Elazığ) çevresinin jeolojisi, Pamukkale Üniversitesi Mühendislik Bilimleri Dergisi, 10(1), 41-50.

Kaymakci, N., Inceöz, M. ve Ertepinar, P. (2006). 3D architecture and neogene evolution of the Malatya basin: inferences for the kinematics of the Malatya and Ovacik fault zones. Turkish Journal of Earth Sciences 15, 123-154.

Kaymakci, N., Inceöz, M., Ertepinar, P. ve Koc, A. (2010). Late cretaceous to recent kinematics of SE Anatolia (Turkey), In: Sosson, M., Kaymakci, N., Stephenson, R., Starostenko, V., Bergerat, F. (Eds.), Sedimentary Basin Tectonics from the Black Sea and Caucasus to the Arabian Platform. Geological Society London Special Publications, 340 , 409-435, http://dx.doi.org/10.1144/SP340.18.

Kennett, J.P., Cannariato, K.G., Hendy, I.L. ve Behl, R.J. (2003). Methane hydrates in quaternary climate change: the Clathrate Gun Hypothesis. Washington DC: American Geophysical Union Special Publication, 54, 216, http://dx.doi.org/10.1029/054SP.

Ketin, İ. (1966). Anadolu'nun tektonik birlikleri, Maden Tetkik ve Arama Dergisi, 66, 20-34.

Kim, G.Y. ve Kim, D.C. (2001). Comparison and correlation of physical properties from the plain and slope sediments in the Ulleung Basin, East Sea (Sea of Japan). Journal of Asian Earth Sciences, 19(5), 669-681, https://doi.org/10.1016/S1367-9120(00)00062-6.

Koçyiğit, A., Aksoy, E. ve İnceöz, M. (2003). Basic Neotectonic Characteristics of the Sivrice Fault Zone in the Sivrice-Palu area, East Anatolian Fault System (EAFS), Turkey, Excursion Guide Book, International Workshop on the North Anatolian, East Anatolian and Dead Sea Fault Systems: Recent Progress in Tectonics and Palaeoseismology, METU (Ankara, Turkey).

Kokum, M., ve Inceoz, M. (2018). Structural analysis of the northern part of the East Anatolian Fault System. Journal of Structural Geology, 114, 5563, https://doi.org/10.1016/j.jsg.2018.06.016.
Kopf, A.J., Stegmann S., Garziglia, S., Henry, P., Dennielou, B., Haas, S. and Weber, K.C. (2016). Soft sediment deformation in the shallow submarine slope off Nice (France) as a result of a variably charged Pliocene aquifer and mass wasting processes. Sedimentary Geology, 344, 290-309,

https://doi.org/10.1016/j.sedgeo.2016.05.014.

Korup, O. (2012). Earth's portfolio of extreme sediment transport events. Earth Sciences Review, 112(34), $115-125$, https://doi.org/10.1016/j.earscirev.2012.02.006.

Kuscu, I., Okamura, M., Matsuoka, H., Yamamori, K., Awata, Y. ve Özalp, S. (2009). Recognition of active faults and stepover geometry in Gemlik Bay, Sea of Marmara, NW Turkey. Marine Geology, 260(1-4), 90-101, https://doi.org/10.1016/j.margeo.2009.02.003.

Lee, C., Yun, T.S., Lee, J.S., Bahk, J.J. ve Santamarina, J.C. (2011). Geotechnical characterization of marine sediments in the Ulleung Basin, East Sea. Engineering Geology, 117(1-2), 151-158, https://doi.org/10.1016/j.enggeo.2010.10.014.

Lee, H.J. (2009). Timing of occurrence of large submarine landslides on the Atlantic Ocean margin. Marine Geology, 264(1-2), 53-64, https://doi.org/10.1016/j.margeo.2008.09.009.

Lee, H.J., Chun, S.S., Yoon, S.H. ve Kim, S.R. (1993). Slope stability and geotechnical properties of sediment of the southern margin of Ulleung Basin, East Sea (Sea of Japan). Marine Geology, 110(12), 31-45, https://doi.org/10.1016/00253227(93)90103-3.

Lipman, P.W., Normark, W.R., Moore, J.G., Wilson, J.B. ve Guatmacher, C.E. (1988). The giant submarine Alika debris slide, Mauna Loa. Hawaii. Journal of Geophysical Research Atmospheres, 93(B5), 4279-4299, https://doi.org/10.1029/JB093iB05p04279.

Locat, J. (2001). Instabilities along ocean margins: a geomorphological and geotechnical perspective. Marine and Petroleum Geology, 18(4), 503-512, https://doi.org/10.1016/S0264-8172(00)00076-3.

Locat, J. ve Lee, H.J. (2002). Submarine landslides: advances and challenges. Canadian Geotechnical Journal, 39, 191-212, https://doi.org/10.1139/t01089.

Locat, J., Leroueil, S., Locat, A. ve Lee, H. (2014). Weak layers: their definition and classification from a geotechnical perspective, In: Krastel S, Berhmann JH, Volker D, Stipp M, Berndt C, Urgeles R, Chaytor JD, Huhn K, Strasser M, Harbitz CB (eds) Submarine mass movements and their consequences, Switzerland: Springer International Publishing. 
Lu, N., Ristow, G.H. ve Likos, W.J. (2000). The accuracy of hydrometer analysis for fine-grained clay particles. Geotechnical Testing Journal, 23(4), 487-495, https://doi.org/10.1520/GTJ11069J.

Lyberis, N., Tekin, Y., Chorowicz, J., Kasapoğlu, E. ve Gündoğdu, N. (1992). The East Anatolian Fault: an oblique collisional belt. Tectonophysics, 204(1-2), 1-15, https://doi.org/10.1016/00401951(92)90265-8

Ma, Z., Merkus, H.G., de Smet, J.G.A.E., Heffels, C. ve Scarlett, B. (2000). New developments in particle characterization by laser diffraction: size and shape. Powder Technology, 111(1-2), 66-78, https://doi.org/10.1016/S0032-5910(00)00242-4.

Maltman, A. (Ed.) (1994). The geological deformation of sediments. Dordrecht: Springer.

Maslin, M., Owen, M., Day, S. ve Long, D. (2004). Linking continental slope failures and climate change: testing the clathrate gun hypothesis. Geology, 32(1), 53-56, https://doi.org/10.1130/G20114.1.

Masson, D.G. (1996). Catastrophic collapse of the volcanic island of Hierro $15 \mathrm{ka}$ ago and the history of landslides in the Canary Islands. Geology, 24(3), 231-234, https://doi.org/10.1130/00917613(1996)024<0231:CCOTVI>2.3.CO;2.

Masson, D.G., Harbitz, C.B., Wynn, R.B., Pedersen, G. ve Løvholt, F. (2006). Submarine landslides: processes, triggers and hazard prediction. Philosophical Transactions of the Royal Societya, 364(1845), 2009-2039, https://doi.org/10.1098/rsta.2006.1810.

McAdoo, B.G., Pratson, L.F. ve Orange, D.L. (2000). Submarine landslide geomorphology, US continental slope. Marine Geology, 169(1-2), 103-136, https://doi.org/10.1016/S00253227(00)00050-5.

Middleton, G.V. ve Hampton, M.A. (1973). Sediment gravity flows: Mechanics of flow and deposition. Middleton, G.V. and Bouma, A.H. (Ed.), Turbidites and Deep Water Sedimentation (pp. 138). California: SEPM Short Course Notes.

Moreno, D.G., Ferrari, A.H., Moernaut, J., Fraser, J.G., Boes, X., Van Daele, M., Avsar, U., Çagatay, N. ve De Batist, M. (2011). Structure and recent evolution of the Hazar basin: a strike-slip basin on the east Anatolian Fault, Eastern Turkey. Basin Research, 23, 191-207, https://doi.org/10.1111/j.13652117.2010.00476.x.

Moscardelli, L. ve Wood, L. (2016). Morphometry of mass-transport deposits as a predictive tool. GSA Bulletin, 128(1-2), 47-80, https://doi.org/10.1130/B31221.1.
Mountjoy, J. ve Micallef, A. (2018). Submarine Geomorphology, Chapter: Landslides, Springer International Publishing, https://doi.org/10.1007/978-3-319-57852-1_13.

MTA, (2008). DAF boyu jeoloji haritasl, Palu ve Şiro Bölütü. Ankara: Maden Tetkik Arama.

MTA, (2012). 1/250000 Ölçekli Türkiye diri fay harita serisi, Elazığ Paftası, Seri No: 45. Ankara: Maden Tetkik Arama.

Mulder, T., Tisot, J.-P., Cochonat, P. ve Bourillet, J.-F. (1994). Regional assessment of mass failure events in the Baie des Anges, Mediterranean Sea. Marine Geology, 122(1-2), 29-45, https://doi.org/10.1016/0025-3227(94)90203-8.

Mulder, T. ve Moran, K. (1995). Relationship among submarine instabilities, sea level variations and the presence of an ice shett on the continental shelf: an example from the Verrill Canyon area, Scotian Shelf. Palaeogeography and Paleoclimatology, 10(1), 137-154, https://doi.org/10.1029/94PA02352.

Mulder, T. ve Alexander, J. (2001). The physical character of subaqueous sedimentary density flows and their deposits. Sedimentology, 48(2), 269-299, https://doi.org/10.1046/j.13653091.2001.00360.x.

Nalbant, S.S., McClosky, J., Steacy, S. ve Barka, A.A., (2002). Stres accumulation and increased seismic risk in Eastern Turkey. Earth Planetary Science Letters, 195, 291-298.

Nardin, T.R., Hein, F.J., Gorsline, D.S. ve Edwards, B.D. (1979). A review of mass movement processes, sediment and acoustic characteristics, and contrasts in slope and base-of-slope systems versus canyon-fan-basin floor systems. Doyle, L.J., Pilkey, O. H. (Eds.), Geology of continental slopes (pp.61-73). California: SEPM Special Publication.

Orange, D.L. ve Breen, N.A. (1992). The effects of fluid escape on accretionary wedges 2 . Seepage force, slope failure, headless submarine canyons and vents. Journal of Geophysical Research, 97(B6), 9277-9295, https://doi.org/10.1029/92JB00460.

Prakash, K. ve Sridharan, A. (2012). Classification of Non-Plastic Soils. Indian Geotechnical Journal, 42(2), 118-123, https://doi.org/0.1007/s40098012-0007-5.

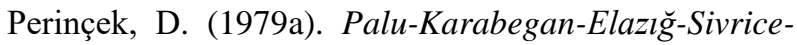
Malatya alanınin jeolojisi ve petrol imkanlart: TPAO arşiv no:1361.

Perinçek, D. (1979b). The geology of Hazro-KorudağÇüngüş-Maden-Ergani-Hazar-Elazı̆̆-Malatya 
Region. Ankara: Geological Society of Turkey, Special Publication.

Piper, D.J.W., Cochonat, P. ve Morrison, M.L. (1999). The sequence of events around the epicentre of the 1929 Grand Banks earthquake: initiation of debris flows and turbidity currents inferred from sidescan sonar. Sedimentology, 46(1), 79-97, https://doi.org/10.1046/j.1365-

3091.1999.00204.x.

Prior, D.B., Bornhold, B.D., Coleman, J.M. ve Bryant, W.R. (1982a). Morphology of a submarine slide, Kitimat Arm. British Columbia. Geology, 10(11), 588-592. https://doi.org/10.1130/00917613(1982)10<588:MOASSK>2.0.CO;2

Rajasekaran, G. (2006). Influence of microfossils and pyrites on the behaviour of oceanbed sediments. Ocean Engineering, 33(3-4), 517-529, https://doi.org/10.1016/j.oceaneng.2005.02.015.

Sarı, E. ve Çağatay, M.N. (2001). Distributions of heavy metals in the surface sediments of the Gulf of Saros, NE Aegean Sea. Environment International, 26(3), 169-173, https://doi.org/10.1016/S0160-4120(00)00097-0.

Sarı, E. ve Çağatay, M.N. (2006). Turbidites and their association with past earthquakes in the deep Çınarcık Basin of the Marmara Sea. GeoMarine Letters, 26, 69-76, https://doi.org/10.1007/s00367-006-0017-3.

Shanmugam, G. (2000). 50 years of the turbidite paradigm (1950s-1990s): deep-water processes and facies models - a critical perspective. Marine and Petroleum Geology, 17(2), 285-342, https://doi.org/10.1016/S0264-8172(99)00011-2.

Stegmann, S. (2007). Design of a free-fall penetrometer for geotechnical characterisation of saturated sediments and its geological application, Doctoral Thesis, Faculty of Geosciences of Bremen University, Germany.

Stegmann, S. ve Kopf, AJ. (2017). Marine deep-water free-fall $\mathrm{Cpt}$ measurements for landslide characterisation off crete, Greece (Eastern Mediterranean Sea) Part 1: A New 4000M Cone Penetrometer. Submarine Mass Movements and Their Consequences, Publishing Springer, 171177, https://doi.org/10.1007/978-1-4020-65125_18.

Stegmann, S., Mörz, T. ve Kopf, A.J. (2006). Initial results of a new Free Fall-Cone Penetrometer (FFCPT) for geotechnical in situ characterisation of soft marine sediments. Norwegian Journal of Geology 86(3), 199-208.

Strozky, F., Strasser, M., Förster, A., Kopf, A. ve Huhn, K., (2010). Slope failure repetition in active magrin environments-constraints from submarine landslides in the Hellenic forearc, eastern Mediterranean. Journal of Geophysical Research, 115(B8), 103 , https://doi.org/10.1029/2009JB006841.

Sungurlu, O., Perinçek, D., Kurt, G., Tuna, E., Dülger, S., Çelikdemir, E. ve Naz, H. (1985). Elazı̆̆-Palu Alanının Jeolojisi. T.C. Petrol İsleri Genel Müdürlüğ̈̈ Dergisi, 29, 83-190.

Şaroğlu, F., Emre, O. ve Kuşçu, I. (1992). The East Anatolian fault zone of Turkey. Annalae Tectonicae, 6, 99-125.

Şengör, A.M.C., Görür, N. ve Şaroğlu, F. (1985). Strikeslip faulting and related basin formation in zones of tectonic escape: Turkey as a case study. K.T. Biddle ve N. Christie-Blick (Ed.), Strike-slip Faulting and Basin Formation (pp. 227-267). Tulsa: SEPM Special Publication.

Talling, P.J., Clare, M., Urlaub, M., Pope, E., Hunt, J.E. ve Watt, S.F.L. (2014). Large submarine landslides on continental slopes: geohazards, methane release, and climate change. Oceanography, 27(2), 32-45, https://doi.org/10.5670/oceanog.2014.38.

Tappin, D.R., Grilli, S.T., Harris, J.C., Geller, R.J., Masterlark, T., Kirby, J.T. Shi, F., Ma, G., Thingbaijam, K.K.S. ve Mai, P.M. (2014). Did a submarine landslide contribute to the 2011 Tohoku tsunami? Marine Geology, 357, 344-361, https://doi.org/10.1016/j.margeo.2014.09.043.

Tolun, L., Çagatay, N. ve Carrigan, W.J. (2002). Organic geochemistry and origin of Late Glacial-Holocene sapropelic layers and associated sediments in Marmara Sea. Marine Geology, 190(1-2), 47-60, https://doi.org/10.1016/S0025-3227(02)00342-0.

TUBITAK, (2014). Hazar Gölü'nde (Elazığ) Pleyistosen-Holosen dönemi yüksek çözünürlüklü iklim ve su seviyesi değişimleri. Proje No: $111 \mathrm{Y} 045$.

Urlaub, M., Talling, P.J. ve Masson, D.G. (2013). Timing and frequency of large submarine landslides: implicatinos for understanding triggers and future geohazard. Quaternary Science Reviews, 72, 6382 , https://doi.org/10.1016/j.quascirev.2013.04.020.

Vanneste, M., Forsberg, C.H., Glimsdal, S., Harbitz, C.B., Issler, D., Kvalstad, T.J., Løvholt, F. ve Nadim, F. (2006). Submarine landslides and their consequences: What do we know, what can we do? The Second World Landslide Forum, Proceedings (pp.1-11). Rome.

Vitton, S.J ve Sadler, L.Y. (1997). Particle size analysis of soils using laser light scattering and X-Ray absorption technology. Geotechnical Testing 
$\begin{array}{lll}\text { Journal, } & 20(1), & 63-73,\end{array}$ https://doi.org/10.1520/GTJ11421J.

Wen, B., Aydın, A. ve Aydın-Duzgoren, N.S. (2002). A comparative study of particle size analysis by sieve-hydrometer and laser diffraction methods. Geotechnical Testing Journal, 25(4), 434-442, https://doi.org/10.1520/GTJ11289J.

Westaway, R. (2003). Kinematics of the Middle East and eastern mediterranean updated. Turkish Journal of Earth Sciences, 12(1), 5-46.

Winters, W.J., Dugan, B. ve Collett, T.S. (2008). Physical properties of sediments from Keathley Canyon and Atwater Valley, JIP Gulf of Mexico gas hydrate drilling program. Marine and Petroleum Geology, 25, 896-905, https://doi.org/10.1016/j.marpetgeo.2008.01.018.

Yazgan, E. (1984). Geodynamics Evolution of the Southern Taurides in the Regio. O. Tekeli and M.
C. Göncüoğlu (Ed.), Geology of the Taurus Belt International Symposium (pp. 199-208). Ankara.

Yılmaz, H., Över, S. ve Özden, S. (2006). Kinematics of the East Anatolian Fault zone between Turkoglu (Kahramanmaras) and Celikhan (Adiyaman). Eastern Turkey. Earth Planets Space, 58, 14631473, https://doi.org/10.1186/BF03352645.

Yun, T.S., Narsilio, G.A. ve Santamarina, J.C. (2006). Physical characterization of core samples recovered from Gulf of Mexico. Marine and Petroleum Geology, 23(9-10), 893-900, https://doi.org/10.1016/j.marpetgeo.2006.08.002.

Zhang, Z. ve Tumay, M.T. (1995). Granulometric evaluation of particle size using suspension pressure during sedimentation. Geotechnical Testing Journal, 18 (1), 121-129, https://doi.org/10.1520/GTJ10129J. 